\title{
WORKING
}

paper

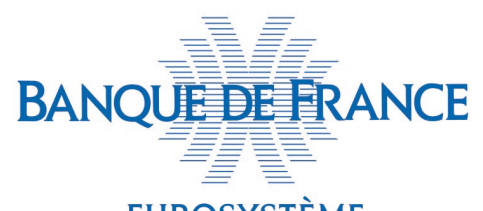

EUROSYSTÈME

\section{French Households' Portfolio: The Financial Almost Ideal Demand System Appraisal}

\author{
Sanvi Avouyi-Dovi ${ }^{1}$, Christian Pfister $^{2} \&$ \\ Franck Sédillot ${ }^{3}$
}

September 2019, WP \# 728

\begin{abstract}
Over the last decades, the composition of financial wealth of French households has dramatically changed. We seek explanatory factors for these changes by estimating an extended version of Deaton and Muellbauer (1980) model applied to French households' portfolio choices. We find that most of the estimated parameters of the benchmark model are in line with economic priors. In particular, wealth and real returns are the key determinants of the long run dynamics of the different asset shares in the portfolio. We use the model to simulate the effect on French households' portfolio allocation for the replacement in 2018 of the various tax regimes of most financial products with a flat tax on savings income. We find that the flat tax should support investment in equities at the expense of life insurance contracts.
\end{abstract}

Keywords: model, return, saving, wealth.

JEL classification: C32, C51, E21

\footnotetext{
${ }^{1}$ Banque de France and ICN Business School, sanvi.avouyi-dovi@,banque-france.fr

2 Banque de France and Sciences Po, christian.pfister@banque-france.fr

${ }^{3}$ Banque de France, franck.sedillot@, banque-france.fr

The authors are grateful to Kadadji T. for his research assistance. They also thank Glachant J. for his comments and suggestions.
}

The views expressed in this paper are those of the authors and should not be interpreted as reflecting the views of the Banque de France, the Eurosystem, ICN Business School or Sciences Po. This document is available on publications.banque-france.fr/en 


\section{NON-TECHNICAL SUMMARY}

French households have sharply increased their accumulation of financial wealth over the last three decades. In addition, the structure of households' financial portfolio greatly evolved over the period 1978-2016. For instance, currency plus overnight deposits and short-term saving deposits accounted for 58\% of total financial wealth in 1978 and only around 30\% in 2016. Life insurance contracts accounted for 4\% of total financial wealth in 1978; about three decades later, this asset represents $44 \%$ of French households' portfolio. This paper seeks to find explanatory factors of these changes. For this purpose, the choice of a model structure has to be made.

In this paper, following Blake (2004), we apply a financial AIDS (FAIDS) framework to French households' portfolio choices. This framework is an extension of the seminal AIDS model of Deaton and Muellbauer (1980) to the financial portfolio. Such a model is compatible with the analysis of households' portfolio choices based on the neoclassical demand theory. In particular, the analysis of cross-interest rate elasticities enables us to assess substitution or complementarity effects between the different asset shares in households' portfolios.

We aggregate the individual financial assets to distinguish six categories of assets within French households' total financial wealth (Banque de France, 2005; Bachellerie et al., 2016). Thus, the share of asset " $i, i=1, \ldots, 6$ " represents the relative weight of this asset in total financial wealth (M1, M2M1, M3M2, PEL, ASSETS, LIFEBONDS). The six shares are the following:

- Currency plus overnight deposits, labelled "M1";

- Short-term savings accounts and deposits with an agreed maturity up to 2 years, labelled "M2M1";

- Money market fund shares, labelled "M3M2";

- Home savings plans (Plans d'épargne logement, PEL), labelled "PEL";

- Equities and non-money market fund shares, labelled "Assets ";

- The sum of life insurance contracts, long-term savings plans in securities distributed by banks (Plan d'Épargne Populaire, PEP), and debt securities held directly by households, labelled "Lifebonds".

There are six shares but the baseline model is a dynamic system of only five equations. In order to meet adding-up conditions requirements imposed by demand theory (Blake, 2004), we drop one equation (the share of PEL, which is relatively weak) from the dynamics system and infer its parameters from the restrictions conditions. We add two exogenous variables (uncertainty or risk factor and business cycle factor). The system is estimated with three-stage least squares over the sample 1999-2016.

We find that each asset is significantly and positively correlated with its own return. We also find cross-effects between real returns and financial assets, with substitution effects prevailing overall. As regards wealth elasticity, it is notable that there is a strong positive effect of wealth on Lifebonds. Conversely, we note a negative link between some financial assets (M1, M3M2), of a liquid nature, and wealth. According to Blake (2004), these assets are wealth-inferior assets with a long run negative elasticity. Finally, only M1 is significantly correlated with the business cycle. Unexpectedly, the other shares, especially the Assets one, are not significantly impacted by real or financial risk factors.

We use the empirical model to simulate the effect on French households' portfolio allocation of the replacement in 2018 of the various tax regimes of most financial products with a flat tax (FT) on savings income. Furthermore, the effects of a scenario, which we label "Extended FT" and in which the FT would be extended to all financial products (Pfister, 2018), are also shown. The long-term impacts on outstanding amounts at end-2017 are displayed in the Table below. In the 
long run, the FT would lead to a substitution out of Lifebonds and, to a lesser extent, M2M1 and M3M2 into Assets and, to a lesser extent, M1, with PEL being unaffected. An "Extended FT" would also cover so-called A passbooks included in M2M1. The column "Extended FT" in the Table below shows that the substitutions resulting from the FT as it stands would be strengthened if the FT were extended to all financial products' income.

Impact of a flat tax on savings income

(Deviation from baseline, in percentage points and EUR billions)

\begin{tabular}{ccccc}
\hline & \multicolumn{2}{c}{ FT } & \multicolumn{2}{c}{ Extended FT } \\
\hline & Share & $€$ Amount & Share & $€$ Amount \\
\hline M1 & 0,2 & 7,3 & 0,3 & 10,9 \\
M2M1 & $-0,1$ & $-4,4$ & $-0,4$ & $-16,0$ \\
M3M2 & $-0,2$ & $-7,9$ & $-0,1$ & $-1,8$ \\
PEL & 0,0 & $-1,4$ & $-0,1$ & $-1,9$ \\
Assets & 0,8 & 31,5 & 0,9 & 34,0 \\
Lifebonds & $-0,7$ & $-25,2$ & $-0,7$ & $-25,2$ \\
\hline
\end{tabular}

\section{Le portefeuille des ménages français : une évaluation à l'aune d'un système de demande quasi-idéal}

\section{RÉSUMÉ}

$\mathrm{Au}$ cours des trois dernières décennies, la composition du patrimoine financier des Français a beaucoup changé. Nous recherchons les facteurs explicatifs de ces changements en estimant une version élargie du modèle de Deaton et Muellbauer (1980) appliqué aux choix de portefeuille des ménages français. Nous trouvons que la plupart des paramètres estimés du modèle de référence sont cohérents avec la théorie. En particulier, la richesse et les rendements réels sont les déterminants-clés des parts des différents actifs dans le portefeuille. Nous utilisons le modèle pour simuler l'effet sur l'allocation de portefeuille des ménages français du remplacement en 2018 des différents régimes fiscaux de la plupart des produits financiers par un prélèvement forfaitaire unique sur les revenus de l'épargne. Nous trouvons que le prélèvement forfaitaire devrait soutenir l'investissement en actions au détriment des contrats d'assurance vie.

Mots-clés : modèle, rendement, épargne, richesse. 


\section{Introduction}

French households have sharply increased their accumulation of financial wealth over the last three decades. While their financial wealth represented less than 5 times their disposable income at the end of 1980, the ratio of wealth to disposable income reached around 11 at the end of 2016. In addition, the structure of households' financial portfolio greatly evolved over the period 1978-2016. For instance, currency plus overnight deposits and short-term saving deposits accounted for $58 \%$ of total financial wealth in 1978 and only around $30 \%$ in 2016. Life insurance contracts accounted for $4 \%$ of total financial wealth in 1978; and about three decades later, this asset represents $44 \%$ of French households' portfolio. This paper aims to model these changes. For this purpose, the choice of a functional form has to be made.

In recent decades, many demand functions consistent with economic theory have been examined in the literature (see for example Barr and Cuthbertson, 1991). Most of them have been described as flexible functional forms based on the duality theory. The most popular demand functions are the generalised Leontief functions (Diewert, 1971), the translog function (Christensen et al., 1975), the Rotterdam model (Theil, 1965 and 1975a, 1975b or Barten, 1964 and 1977) and the Almost Ideal Demand System (AIDS, Deaton and Muellbauer, $1980 \mathrm{a}$ and b).

These functions share similar characteristics and are typified by the absence of some of the $a$ priori restrictions on elasticities that guarantee the local flexibility of previously developed functions. In addition, one of the main advantages of these functions is the relatively small number of their parameters, which means that all the expected elasticities can be approximated. However, these functional forms can also have some drawbacks; in particular, they are only consistent with microeconomic theory requirements in small regions.

To circumvent these drawbacks, alternative flexible functional forms have been developed. These new functional forms aim to enlarge the regions in which these functions are consistent with the microeconomic theoretical framework. As a result, they are more general and more relevant. For illustration purposes, the quadratic almost ideal demand system, the Laurent model and the generalised exponential functional form, respectively initiated by Banks et al. (1987), Barnett et al. (1987) and Cooper and McLaren (1996), are worth mentioning.

In addition, in order to guarantee the ability to approximate asymptotically the elasticities included in the models at each data point, semi- and non-parametric approaches have also been implemented. These new generation approaches are conceptually attractive but also more sophisticated and complex. In addition, performing a profit and loss analysis would be necessary in order to properly assess the benefits accruing from the use of these frameworks in terms of their empirical relevance. However, although there are many papers which discuss the properties of some specific and complete demand systems, only a few studies have been devoted to a systematic and thorough comparison of demand systems (see among others, Pollack and Wales, 1978 and 1980, Lewbel, 1989, Alston and Chalfan, 1993, Lee et al., 1994, Kastens and Brester, 1996, and more recently, Fousekis and Revell, 2000 and 2003, Katchova and Chern, 2004, Erkan, 2006, Barnett and Seck, 2008 and Meyer et al. 2011).

Hence, the problem of tractability is often solved by linearising some functions, derived under some acceptable theoretical restrictions. For example, the linear AIDS models (Deaton and Muellbauer, $1980 \mathrm{a}$ and b) or the linear Rotterdam models (Theil, 1965 and $1975 \mathrm{a}$ and b or Barten, 1964 and 1977) are regularly estimated, especially in applied microeconomic studies. It is worth noting that one of the advantages of both the AIDS and Rotterdam models is that they have recourse to theoretical restrictions that are statistically testable rather than impose them on the functional form.

Barnett and Seck (2008) show that there is no definite evidence of the predominance of the AIDS models over the Rotterdam models in terms of explanatory power or forecasting 
performances. For example, the two classes of models perform well when substitution among goods is low. Also, according to their findings, the full non-linear AIDS models by Deaton and Muellbauer (1980 a and b) perform better than the original Rotterdam models in certain cases, whereas the Rotterdam ones clearly exceed the AIDS models in other cases. Their performances are not dependent on the index used especially in the linearisation process. In particular, the full non-linear AIDS models perform better than their linear versions. In addition, this dominance does not depend on the index. To our knowledge, the comparisons made in Barnett and Seck (2008) were not extended to more general approaches or to the new generation of functional forms.

It is therefore not possible to dissociate the performances of the two classes (AIDS and Rotterdam) of demand functions. Furthermore, by comparing the AIDS and Rotterdam models using a model selection procedure (Amemiya, 1980, 1985), Erkan (2006) finds that the AIDS model displays better performances than the Rotterdam model. One can therefore adopt either one of the two approaches without the conviction that it is the best choice whatever the circumstances.

As the aim of the paper is not to compare different demand systems, our selection of the demand system is guided by the best practices in this research area. Thus, the main guideline of our study is given by the robustness and stability of the empirical results from previous studies. As mentioned before, the AIDS models deliver relatively good performances under some conditions in many empirical studies. The appropriate framework should be clearly microfounded in order to avoid some spurious relations. Finally, it should be empirically tractable and intuitively understandable. The AIDS model meets these requirements and is a good tradeoff between the different classes of demand systems.

In this paper, we apply a financial AIDS (FAIDS) framework, pioneered by Blake (2004), to French households' portfolio choices (see also Barr and Cuthbertson, 1994). This framework is an extension of the seminal AIDS model of Deaton and Muellbauer (1980 a and b) to the financial portfolio (see also Grimes et al., 1994). Such a model is compatible with the analysis of households' portfolio choices based on the neoclassical demand theory. In particular, the analysis of cross-interest rate elasticities enables us to assess substitution or complementarity effects between the different asset shares in households' portfolios.

We find that most of the estimated parameters of the benchmark model are in line with economic priors. In particular, wealth and returns are the key determinants of the long run dynamics of the different shares. Moreover, some additional exogenous factors improve the general performance of the model, highlighting the role of risk and business cycle factors in the changes in the structure of French households' portfolio. The main results remain valid under some alternative assumptions implemented in the context of some robustness checks.

This paper is organised as follows: Section 2 explores the theoretical background of the demand systems; Section 3 outlines the empirical models; Section 4 provides some specific features of the data used in the empirical work; Section 5 examines the results of the estimation; Section 6 summarises the conclusions of the robustness checks; Section 7 uses the empirical model to describe the effect of interest rates staying at the current very low levels on households' portfolio allocation. Section 8 outlines the long run effects of the recent introduction of a flat tax on French households' portfolio. Section 9 concludes. 


\section{Theoretical background}

\subsection{Theory underpinning the AIDS models}

The objective of a representative agent is to maximise his/her expected utility function subject to his/her expected budget constraint. Rather than this maximisation, Deaton and Muellbauer (1980 a and b) propose minimising the associated cost function by deriving the optimal long run portfolio weights. In this paper, we focus on these long run weights.

According to Blake (2004), the objective of a representative agent can be written as follows:

$$
\left\{\begin{array}{l}
\operatorname{Max}^{e}\left(\theta_{1 t} W_{t}, \ldots, \theta_{N t} W_{t}\right) \\
W_{t+1}^{e}=\sum_{i=1}^{N} \theta_{i t} W_{t}\left(1+r_{i t}^{e}\right)
\end{array}\right.
$$

Where:

$X^{e}$ means expected value of $X$;

$U^{e}$ is the expected utility function of a representative agent;

$W_{t}$ represents real wealth at time t;

$\theta_{i t}$ is the weight in the portfolio (share) of the $\mathrm{i}^{\text {th }}$ asset category $(\mathrm{i}=1, \ldots, N)$ at time $\mathrm{t}$;

$r_{i t}$ is the real return on the $\mathrm{i}^{\text {th }}$ asset category at time $\mathrm{t}$;

$N$ is the number of asset categories in the portfolio of a representative agent.

More precisely, according to Deaton and Muellbauer, replacing the maximisation of the utility function by the minimisation of a cost function using a PIGLOG functional form leads to long run (optimal, $\theta_{i t}^{*}$ ) portfolio weights defined by:

$$
\begin{aligned}
& \theta_{i t}^{*}=a_{i}^{*}+b_{i}^{*} \ln \left(W_{t}\left(1+r_{w t}^{e}\right)\right)+\sum_{j=1}^{N} c_{i j}^{*} \ln \left(1+r_{j t}^{e}\right)=a_{i}^{*}+b_{i}^{*} \ln \left(W_{t}\right)+b_{i}^{*} \ln \left(1+r_{w t}^{e}\right)+ \\
& \sum_{j=1}^{N} c_{i j}^{*} \ln \left(1+r_{j t}^{e}\right)
\end{aligned}
$$

$r_{W t}$ is an index measuring the return of the set of assets in the portfolio. It is defined by:

$$
\ln \left(1+r_{w t}^{e}\right)=a_{0}^{*}+\sum_{1}^{N} a_{j}^{*} \ln \left(1+r_{j t}^{e}\right)+\sum_{i=1}^{N} \sum_{j=1}^{N} c_{i j}^{*} \ln \left(1+r_{i t}^{e}\right) \ln \left(1+r_{j t}^{e}\right) \quad \text { (Equation 2) }
$$

As $r_{j t}^{e}$ is overall very small compared to 1 , the cross-product term (in $r_{j t}^{e}$ ) is negligible and can be dropped. In addition, if $a_{0}^{*}=0$ and $a_{j}^{*}=\theta_{j}$ (weight of asset $\mathrm{i}$ at $\mathrm{t}=0$ ), $r_{w t}^{e}$ is the expected return on the assets. It is the value-weighted average expected return on assets held in the portfolio, equivalent to the Stone index. However, another approximation can be made. Indeed, it is possible to introduce some alternative indexes in the derivation of the portfolio optimal weights ${ }^{4}$.

Replacing $\ln \left(1+r_{w t}^{e}\right)$ in the equations of portfolio optimal weights (see Equation 1) by its approximation and re-parameterising the relations enables us to marginally transform the original equations. Moreover, it leads to more complex elasticities of the weights relative to the real returns. For example, we can refer to the model by Barnett and Seck (2008) which is similar to the FAIDS model presented above. Barnett and Seck (2008) provide an expression of the Marshallian price elasticities which mainly depends on the budget shares (see Box 1).

\footnotetext{
${ }^{4}$ For example, the Törnqvist index (Törnqvist, 1936) helps to circumvent some drawbacks of the Stone index. However, we do not use it for simplicity purposes.
} 
Box 1: The full AIDS Model in Budget Shares

According to Barnett and Seck (2008), the full AIDS model in budget shares can be written:

$$
\mathrm{w}_{\mathrm{it}}=\alpha_{\mathrm{i}}+\sum_{\mathrm{k}=1}^{\mathrm{L}} \gamma_{\mathrm{ik}} \log \mathrm{p}_{\mathrm{kt}}+\beta_{\mathrm{i}} \log \left(\frac{\mathrm{I}_{\mathrm{t}}}{\mathrm{P}_{\mathrm{t}}}\right)
$$

Where $\mathrm{p}_{\mathrm{k}}$ is the price of good $k$; $\mathrm{L}$ is the number of goods; and the deflator $(P)$ of income $(I)$ is defined by:

$$
\begin{gathered}
\log \left(\mathrm{P}_{\mathrm{t}}\right)=\alpha_{0}+\sum_{\mathrm{k}=1}^{\mathrm{L}} \alpha_{\mathrm{k}} \log \mathrm{p}_{\mathrm{kt}}+\frac{1}{2} \sum_{\mathrm{k}=1}^{\mathrm{L}} \sum_{\mathrm{j}=1}^{\mathrm{L}} \gamma_{\mathrm{kj}}^{*} \log \mathrm{p}_{\mathrm{kt}} \log \mathrm{p}_{\mathrm{jt}} \\
\text { And } \gamma_{\mathrm{ik}}=\frac{1}{2}\left(\gamma_{\mathrm{ik}}^{*}+\gamma_{\mathrm{ki}}^{*}\right)
\end{gathered}
$$

Restrictions linked to some long run perspectives (respectively for adding up, linear homogeneity and symmetry assumptions) are deduced from the cost function, in line with the demand theory. They can be defined as follows:

- $\quad \sum_{\mathrm{k}=1}^{\mathrm{L}} \alpha_{\mathrm{k}}=1$. This identity stands for the adding up requirement;

- $\quad \sum_{\mathrm{k}=1}^{\mathrm{L}} \mathrm{b}_{\mathrm{k}}^{*}=0$ and $\sum_{\mathrm{k}=1}^{\mathrm{L}} c_{i k}^{*}=0$. These equalities stand for the linear homogeneity hypothesis;

- $\quad c_{\mathrm{kj}}^{*}=\mathrm{c}_{\mathrm{jk}}^{*}$, whatever $\mathrm{j}$ and $\mathrm{k}$. The equalities between these parameters are associated with the symmetry assumption.

Imposing these assumptions implies that the redundancy of some of the model's parameters is eliminated.

Barnett and Seck (2008) show that the shares equations can be interpreted as a Marshallian or uncompensated demand function which makes it possible to solve the utility maximisation problem. Using the Slutsky equation in elasticities, it is therefore possible to obtain the Hicksian price elasticities drawn from the Marshallian price elasticities. The expression of the Marshallian price elasticities by Barnett and Seck (2008) is shown below. It mainly depends on the budget shares and the parameters in the dynamic explanatory system. This expression takes the following form (elasticity of good $i$ with respect to good $\mathrm{j}$ ):

$$
\varepsilon_{\mathrm{ij}}^{\mathrm{M}}=-\delta_{\mathrm{ij}}+\frac{1}{\mathrm{w}_{\mathrm{i}}}\left[\gamma_{\mathrm{ij}}-\beta_{\mathrm{i}}\left(\alpha_{\mathrm{j}}+\sum_{\mathrm{k}=1}^{\mathrm{L}} \gamma_{\mathrm{kj}} \log \mathrm{p}_{\mathrm{k}}\right)\right]
$$

with $\delta_{\mathrm{ij}}=1$ if $\mathrm{i}=\mathrm{j} ; \quad \delta_{\mathrm{ij}}=0$ otherwise.

Barnett and Seck (2008) also provide the formulas of the correct Marshallian price elasticities and income elasticities when the demand system is the linear approximated AIDS.

According to Barnett and Choi (1989), the AIDS models make it possible to test some technical properties and thereby impose some meaningful restrictions on elasticities. 


\subsection{A brief snapshot of the augmented AIDS}

The original AIDS aims at singling out so-called "long run elasticities". However, due to the statistical properties of the shares, a direct estimation of such a specification leads to unsatisfactory results. In order to take into account the statistical properties of the data, we modify the model. Several approaches exist in the empirical econometric literature.

To capture data properties, it is usual to assume that budget shares follow stochastic trends with some seasonal effects (Moosa et al., 2002). Clearly, it is possible to test the relevance of the presence of a stochastic trend in the data. The seasonal factor in the shares equations is deterministic. In this paper, we use seasonally adjusted data and the presence of stochastic trends is not validated. We do not therefore need to introduce seasonal factors or stochastic trends in our framework.

Another strand of the literature on the AIDS approach is the Markov-Switching (MS) AIDS model (MS-AIDS) which is a combination of the AIDS and MS models. This approach makes it possible to detect regime shifts with their corresponding parameters. Even though a Bayesian approach can help, the estimation of this model requires a large data sample.

In this paper, we follow an alternative approach which consists in introducing some exogenous factors in the dynamic framework. With these factors, it is possible to take into account specificities of households' financial environment or more generally their economic situation (life and business cycle factors, risk factors through asset return volatilities, etc.). The selection of these factors is theoretically grounded or based on a strong economic intuition. They may display the same stochastic trends as the shares and should help improve the economic interpretation of the empirical results.

\section{Empirical model}

\subsection{The basic form}

Let us assume that they are $\mathrm{N}$ asset shares and $\mathrm{M}$ additional exogenous variables in our dynamic system. The equations of these asset shares (which are the extension of the previous equations, see Equation 1, with some added exogenous factors) can be expressed as follows:

$$
\theta_{i t}^{*}=a_{i}^{*}+b_{i}^{*} \ln \left(W_{t}\left(1+r_{w t}\right)\right)+\sum_{j=1}^{N} c_{i j}^{*} \ln \left(1+r_{j t}\right)+\sum_{j=1}^{M} h_{i j}^{*} z_{j t}+u_{i t} \quad \text { (Equation 3) }
$$

Where, $\theta_{i t}^{*}, \mathrm{i}=1, \ldots \mathrm{N}$, are the "optimal or long run" shares $\left(\theta_{i t}^{*}\right.$ weight of the $\mathrm{i}^{\text {th }}$ asset in total wealth), $W_{t}$ stands for total wealth, $r_{w t}$ and $r_{j t}$ are real rates of return on wealth and assets respectively; $z_{j t}$ are exogenous factors that aim to capture specific features of financial markets or business and life cycle components.

\subsection{An overview of a way to introduce dynamics in a FAIDS model}

A conventional way to introduce dynamics into a FAIDS model is to add quadratic adjustment costs in Equation 1 (Christofides, 1976; Hunt and Upsher, 1979).

$$
\begin{aligned}
& \underset{\theta}{\operatorname{Min}} \frac{1}{2}\left(\theta_{t}-\theta_{t}^{*}\right)^{\prime} \Omega\left(\theta_{t}-\theta_{t}^{*}\right)+\frac{1}{2}\left(\theta_{t}-\theta_{t-1}\right)^{\prime} \Psi\left(\theta_{t}-\theta_{t-1}\right) \\
& \text { Subject to } l^{\prime}\left(\theta_{t}^{*}-\theta_{t}\right)=0
\end{aligned}
$$


The first part of the objective function represents the cost of being away from the desired share level whilst the second part is the cost of adjusting towards equilibrium. Solving this minimisation programme leads to:

$$
\Delta \theta_{t}=\left(\Phi-\frac{\Phi \Omega^{-1} l l^{\prime} \Phi}{l^{\prime} \Phi \Omega^{-1} l}+\frac{\Phi \Omega^{-1} l l^{\prime}}{l^{\prime} \Phi \Omega^{-1} l}\right)\left(\theta_{t}^{*}-\theta_{t-1}\right) \Leftrightarrow \Delta \theta_{t}=\Lambda\left(\theta_{t}^{*}-\theta_{t-1}\right)
$$

(Equation 4)

Equation 4 describes a partial adjustment model. According to the Bewley transformation (Bewley, 1979), this partial adjustment system can be rewritten in a more compact way:

$$
\theta=\Pi^{*} X+\Lambda^{-1}(I-\Lambda) \Delta \theta
$$

where $\Pi^{*}, X, \Lambda, I$ are conformable matrices or vectors defined as follows:

$$
\begin{aligned}
& \begin{array}{llllllll}
a_{1}^{*} & b_{1}^{*} & c_{1,1}^{*} & \mathrm{~L} & c_{1, N}^{*} & h_{1,1}^{*} & \mathrm{~L} & h_{1, M}^{*}
\end{array} \\
& c_{2,2}^{*} \quad \mathrm{O} \quad c_{2, N}^{*} \\
& \Pi^{*}=\begin{array}{llllllll}
M & M & M & c_{3,3}^{*} & M & M & M & M
\end{array} \\
& \text { O } \mathrm{O} \\
& \begin{array}{llllllll}
a_{N}^{*} & b_{N}^{*} & c_{N, 1}^{*} & \mathrm{~L} & c_{N, N}^{*} & h_{N ; 1}^{*} & \mathrm{~L} & h_{N, M}^{*}
\end{array} \\
& X=X^{\prime}=\left(1, \ln (W(1+r)), \ln \left(1+r_{1}\right) \mathrm{L} \ln \left(1+r_{N}\right), z_{1}, \mathrm{~L}, z_{M}\right) \\
& \Lambda=\left(\Phi-\frac{\Phi \Omega^{-1} l l^{\prime} \Phi}{l^{\prime} \Phi \Omega^{-1} l}+\frac{\Phi \Omega^{-1} l l^{\prime}}{l^{\prime} \Phi \Omega^{-1} l}\right)
\end{aligned}
$$

$N$ is the number of asset shares and $M$ is the number of additional exogenous factors.

Equation 5 has two main advantages: (i) It allows for a direct estimation of long run elasticities and the introduction of some dynamics; (ii) conventional econometric approaches can be applied to estimate the unknown parameters of our model (see below).

We obtain a more general specification of the previous model by introducing $\mathrm{K}$ lags in the partial adjustment model:

$\hat{\theta}=I A+\Pi_{0} X_{0}+\Pi_{-1} X_{-1}+\mathrm{L}+\Pi_{-K} X_{-K}+B \theta_{-1}$

This relation can be rewritten as:

$$
\hat{\theta}=\Pi^{*} X+\left(\left(\Pi_{-1}+\mathrm{L}+\Pi_{-K}\right) \Delta X+(I-B)^{-1}\left(\Pi_{-2}+\mathrm{L}+\Pi_{-K}\right) \Delta X_{-1}+\mathrm{L}+\Pi_{-K} \Delta X_{-K}\right)+(I-B)^{-1} B \Delta \theta
$$

(Equation 6) 
Equation 6 can be interpreted as a conventional partial adjustment model by noting that:

$$
\begin{aligned}
& (I-B)^{-1}=\hat{\Lambda}^{-1},(I-B)^{-1} B=\hat{\Lambda}^{-1}(I-\Lambda) \text { and } \\
& \Pi^{*}=(I-B)^{-1}\left(I A+\Pi_{0} X_{0}+\Pi_{-1} X_{-1}+\mathrm{L}+\Pi_{-K} X_{-K}\right)
\end{aligned}
$$

\subsection{The estimated model}

The specification implemented in the empirical part of the paper is written in the following form:

$$
\begin{gathered}
\theta_{i t}=a_{i}^{*}+b_{i}^{*} \ln \left(W_{t}\left(1+r_{w t}\right)\right)+\sum_{j=1}^{N} c_{i j}^{*} \ln \left(1+r_{j t}\right)+\sum_{j=1}^{M} h_{i j}^{*} z_{j t}+\sum_{s=0}^{K-1} b_{i s}^{*} \Delta \ln \left(W_{t}(1+\right. \\
\left.\left.r_{w_{t-s}}\right)\right)+\sum_{s=0}^{K-1} \sum_{j=1}^{N} c_{i j s}^{*} \Delta \ln \left(1+r_{j_{t-s}}\right)+\sum_{s=0}^{K-1} \sum_{j=1}^{M} h_{i j s}^{*} \Delta \ln \left(z_{j t-s}\right)+\sum_{j=1}^{N-1} \lambda_{i j}^{*} \Delta \theta_{i t}+\zeta_{i t}
\end{gathered}
$$

(Equation 7)

Where:

- $\quad W_{t}$ stands for total wealth;

- $\quad r_{w t}$ and $r_{j t}$ are real rates of return on wealth and assets respectively;

- $z_{j t}$ are additional exogenous factors that aim to capture specific features of financial markets or business and life cycle components;

- $\quad K$ represents the order of the VAR, i.e. the number of lags in the VAR;

- $\quad N$ is the number of asset shares;

- $\quad M$ is the number of additional exogenous factors;

- $\quad i=1, \ldots, N$.

In order to control for simultaneity (Blake, 2004), we derive our empirical equations from a slightly different version of the previous dynamic system. Indeed, our benchmark is based on the transformation of the previous equations by replacing $\sum_{j=1}^{N-1} \lambda_{i j}^{*} \Delta \theta_{i t}$ by $\sum_{j=1}^{N-1} \lambda_{i j}^{*} \Delta \theta_{i t-1}$ in Equation 7.

The baseline model is therefore:

$$
\begin{aligned}
& \theta_{i t}=a_{i}^{*}+b_{i}^{*} \ln \left(W_{t}\left(1+r_{w t}\right)\right)+\sum_{j=1}^{N} c_{i j}^{*} \ln \left(1+r_{j t}\right)+\sum_{j=1}^{M} h_{i j}^{*} z_{j t}+\sum_{s=0}^{K-1} b_{i s}^{*} \Delta \ln \left(W_{t}(1+\right. \\
& \left.\left.r_{w_{t-s}}\right)\right)+\sum_{s=0}^{K-1} \sum_{j=1}^{N} c_{i j s}^{*} \Delta \ln \left(1+r_{j_{t-s}}\right)+\sum_{s=0}^{K-1} \sum_{j=1}^{M} h_{i j s}^{*} \Delta \ln \left(z_{j t-s}\right)+\sum_{j=1}^{N-1} \lambda_{i j}^{*} \Delta \theta_{i t-1}+\zeta_{i t}
\end{aligned}
$$

(Equation 8)

\section{Data sources and descriptive statistics}

We draw most of the interest rates used in this paper from Banque de France and French National Institute of Statistics and Economic Studies (INSEE) databases on a quarterly basis over the period 1978-2016. Real activity factors are drawn from the INSEE database over the whole period. Financial assets data are taken from the Banque de France French quarterly financial accounts dataset on the sample 1995-2016. In order to complement these datasets over the whole period (Q1 $1978-\mathrm{Q} 4$ 2016), we retropolate financial assets on the missing subsample (Q1 1978-Q4 1994).

\subsection{Endogenous variables}

We aggregate the individual financial assets to distinguish six categories of assets within French households' total financial wealth (Banque de France, 2015; Bachellerie et al., 2016). Thus, the 
share of asset " $\mathrm{i}, \mathrm{i}=1, \ldots, 6$ " represents the relative weight of this asset in total financial wealth (M1, M2M1, M3M2, PEL, ASSETS, LIFEBONDS). The six shares are the following (Chart 1):

- Currency plus overnight deposits, labelled "Ml";

- Short-term savings accounts and deposits with an agreed maturity up to 2 years, labelled "M2MI";

- Money market fund shares, labelled "M3M2";

- Home savings plans (Plans d'épargne logement, PEL), labelled "PEL";

- Equities and non-money market fund shares, labelled "Assets ";

- The sum of life insurance contracts, long-term savings plans in securities distributed by banks (Plan d'épargne populaire, PEP), and debt securities held directly by households, labelled "Lifebonds". Several factors justify aggregating these assets: i) Life insurance contracts and PEP contracts display similar features; ii) Many holders of PEP contracts have re-invested their savings in life insurance contracts (Darmon et al., 2005); as a reminder, PEP contracts were introduced in 1990 with no maximum duration and can no longer be subscribed since 2003, although payments can still be made on existing contracts; iii) Around $85 \%$ of all life insurance contracts are invested in debt securities.

Changes in the six categories of assets are shown in Chart 1. Most of the six shares $(M 1, M 2 M 1$, M3M2, PEL, ASSETS, LIFEBONDS) follow integrated processes of order 1 (Appendix, Table A). They display a bi-modal distribution (Appendix, Table B).

Chart1: Strong Changes in the shares of households' portfolio (in pp of total financial wealth)

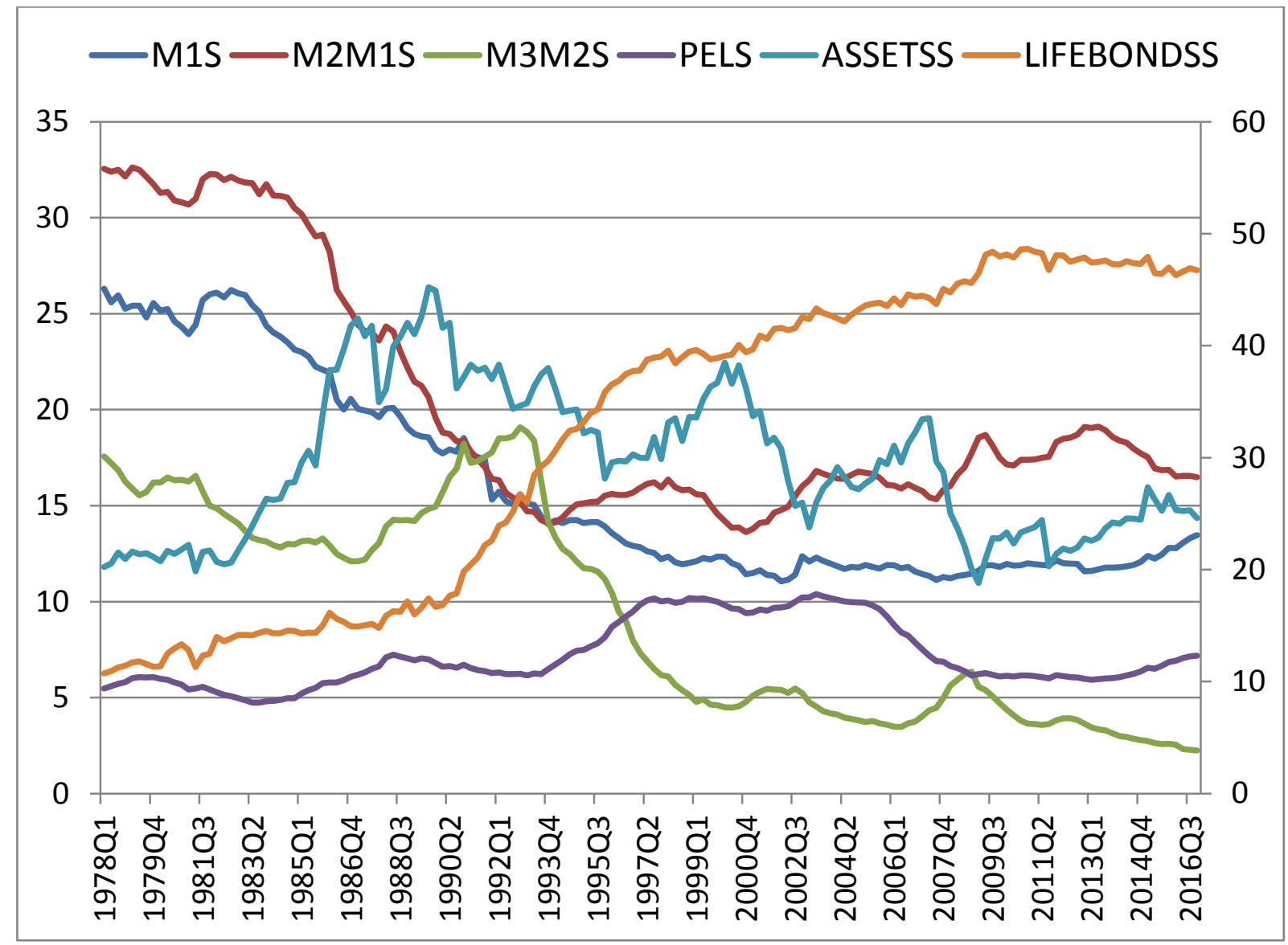

Sources: Banque de France and authors' calculations. All shares except Lifebonds (LHS), Lifebonds (RHs). 
MI decreased from $27 \%$ in 1978 to around $10 \%$ in the early 2000 s before slightly increasing in recent years. On average, $M 1$ reached $15.8 \%$ over the full sample versus $18.2 \%$ over Q1 1978Q4 1998, and respectively 13.0\% and 14.1\% over Q1 1999-Q4 2016 and Q1 2008-Q4 2016. Moreover, M1 was more volatile over the earliest sub-period (Q1 1978-Q4 1998, Appendix Table B).These developments reflect four factors: the increase in wealth, as sight deposits are "inferior goods", either non-remunerated or remunerated at below market rates; the decline in inflation (the yearly increase in the consumer price index (CPI) hovered around $10 \%$ in the late $1970 \mathrm{~s}$ and early $1980 \mathrm{~s}$ and fell sharply from the mid-1980s; it has been above $2.0 \%$ for only one year since 1994) that mitigated the Pigou effect; the development of modern means of payments, especially ATMs and credit cards, from the mid-1980s; and the spreading of financial innovation, in particular money market funds, from the same period. However, since the financial crisis, $M 1$ has been on an upward trend interpreted as a "liquidity trap" and has been induced by very low interest rates.

M2MI also substantially decreased, from more than $30 \%$ in the late 1970 s to around $15 \%$ in the early 1990s. Between 1993 and 2006, it fluctuated around 15\%. An increase in this share from $16 \%$ to $19 \%$ took place between 2007 and early 2009 . This is due to a government decision to allow all banks to distribute a tax free savings account whose distribution was previously restricted to savings banks. Finally, it has displayed a downward trend since Q2 2013 and descriptive statistics confirm this general overview. On average, $M 2 M 1$ is equal to $20.0 \%$ over the full sample versus respectively $23.5 \%, 16.8 \%$ and $17.8 \%$ over the sub-samples Q1 1978-Q4 1998, Q1 1999-Q4 2016 and Q1 2008-Q4 2016. In addition, the standard deviations, associated with the full sample and the earliest sub-period, are higher than those corresponding to the more recent sub-samples.

M3M2, the share of financial assets whose returns are closely related to money market rates, increased sharply between 1986 and 1993 to reach $20 \%$ of total financial wealth. This can be accounted for by the creation and the rapid spreading of money market funds that benefited both from a high level of short-term interest rates in a period of disinflation and exchange rate pressures within the Exchange Rate Mechanism, especially in 1992-1993, and from tax incentives at their inception. Afterwards, M3M2 sharply decreased until 1999 as short-term interest rates declined and tax incentives were removed. Since 2000, the share of M3M2 has been on a gentle downward trend, reaching less than 3\% in 2016 (2.2\% in Q4 2016), although a flight out of riskier assets into more liquid ones created a hump between 2007 and 2010. The mean values and standard deviations calculated over the different sample periods for this share corroborate these general remarks. On average, $M 3 M 2$ stood at $9.5 \%$ over the full sample, $13.9 \%$ over the earliest sub-sample (Q1 1978-Q4 1998) and around 4\% over the more recent period (Q1 2008-Q4 2016).

PEL fluctuated in an interval around 7.2\% (with a standard deviation of less than 0.02). Indeed, PEL increased from 5\% in 1984 to $7 \%$ in 1987 and then from $7 \%$ in 1994 to $10 \%$ in 1997 . It then remained stable until 2006, before decreasing between 2007 and 2009, and edging up in more recent years (from Q3 2013 to Q4 2016), ending at 7.2\% in Q4 2016. Changes in the government regulation applicable to PEL investments (ceiling on deposits, on loans which are accessible after a period of savings, interest rates on deposits and loans, government premium, and tax treatment) played an important role in this evolution. In particular, from 2005, interest payments on PEL contracts opened for 12 years or more were submitted to income tax, whereas they were previously tax free for an unlimited period.

An important factor that accounts for the inertia in PEL is the length of the contract (15 years since February 2011), together with the fact that the interest rate on deposits is set at the opening of the contract and cannot be changed afterwards. However, there is a ceiling (set at EUR $61,200)$ on the sum that can be deposited on a contract. In addition, an individual cannot hold more than one contract. Thus, savers are given a "free" option to both open an account and step up their deposits when market interest rates fall, and close it and open a new one when market 
interest rates increase. The average remuneration of $P E L$ contracts stood at $2.84 \%$ in February 2016, when the government lowered the rate on new PEL contracts to 1\%, and the share of PEL tends to increase when long-term interest rates fall, as was the case following the euro area sovereign debt crisis in 2011-2012.

Assets almost doubled over the period from Q1 1983 to Q3 1989, reaching 26.4\% (the maximum value observed over the full sample). It then fluctuated around a downward trend, reaching around $15 \%$ in 2016 versus an average of $13.2 \%$ over the post-financial crisis subsample and $17.5 \%$ over the full sample. Fluctuations in this share are mainly accounted for by valuation effects, especially those of stock prices. In particular, the CAC40, the index of the 40 most capitalised and traded listed shares on the Paris stock exchange, reached its all-time peak in 2000, with the so-called "dot-com" bubble.

Lifebonds was on a sharp upward trend over the period under review: on average, it reached 21.3\%, 43.8\%, and 46.0\% over Q1 1979-Q4 2016, Q1 1999-Q4 2016 and Q1 2008-Q4 2016 respectively. In particular, it increased sharply, from 18.5\% in Q1 1990 to $39.6 \%$ in Q4 1998, and then more gently to $46.6 \%$ in 2016 . Lifebonds has become the prominent part of total financial wealth since 1992. Its upward trend can be attributed to tax incentives, which have played a major role (Monfront et al., 2005). Two other important factors are demography, as baby boomers reached the peak of their professional careers in the 1990s, and the fall in longterm interest rates in the years preceding the creation of the euro in early 1999.

Overall, the financial turmoil in 2007-2008 and the euro area sovereign debt crisis in 2011-2012 did not have a significant impact on the structure of French households' financial wealth. The bulk of their financial assets remains invested in life insurance contracts and in bank deposits (saving accounts included in $M 2 M 1$, and PEL contracts) whose remuneration is set by the government in a sluggish manner, enjoying in both cases a privileged tax treatment (Bachellerie et al., 2016). Only slight changes have occurred since the last quarter of 2008, with small increases in the shares of $M 1, P E L$ and Assets, and a more significant fall in the share of M3M2.

\subsection{Exogenous factors}

Here, we provide some details regarding the asset returns introduced in the FAIDS model. For $M 1$, we use the apparent interest rate on deposits that is available in the financial accounts for the period 2003-2016. This series is correlated with the money market rate and its level is very low as deposits are mostly non-interest paying assets in France. Indeed, paying interests on deposits was introduced with the harmonisation required at the European level at the time of the monetary unification. However, the number of interest-paying deposit accounts remains quite limited in France. The interest rate on $M 1$ is retropolated on the basis of the money market rate over the sub-period 1978-2002.

We compute a weighted-average return for $M 2 M 1$ based on interest rates for the different shortterm deposits included in it. For $M 3 M 2$, we use the overnight rate. For $P E L$, we use the interest rate set by government ${ }^{5}$.

For Assets, we compute the annualised return on the CAC40 stock market index. As we do not have access to returns on life-insurance contracts on a quarterly basis for the entire sample, the return on Lifebonds is the 10-year yield on Treasuries. Finally, to obtain the real returns, all the previous nominal returns are deflated by the inflation rate drawn from the CPI.

\footnotetext{
${ }^{5}$ An alternative indicator of the PEL return is the average remuneration of the vintages of PEL contracts. Even if this indicator is in line with economic priors, its assessment is based on some more or less realistic assumptions. From this view, the empirical measure of this indicator is not necessarily a good approximation of the PEL return. This is why we privilege a simpler evaluation of this return.
} 
Some additional explanatory factors are also tested in the relationships describing the dynamics of the shares (see Equation 8). Following Blake (2004) or Pollack and Wales (1980), we focus on factors related to: uncertainty or risk; business and life cycles (Box 2). The expected sign of these factors in the shares equations is in general not ambiguous. For example, the ratio of "high savers" positively influences Assets and Lifebonds because the "high savers" are more inclined to diversify their portfolio by increasing the share of riskier and longer-term assets.

Besides, some data (demographic factors, etc.) are available at an annual frequency. We transformed them into quarterly data by applying a smoothing method implemented by the French National Institute of Statistics (INSEE, 2012). In addition, some indicators are based on non-parametric approaches, whereas others are calculated within a more formalised parametric framework (GARCH or stochastic volatility models, etc.). Unlike Black (2004), we test the two kinds of approaches in our applications (see Box 2).

Box 2: Additional exogenous factors

\section{Uncertainty and risk factors}

Real gross disposable income (gross disposable income, GDI, at current prices deflated by consumer price index, CPI), RGDI, over real total financial wealth, RWealth.

Volatility of real income (vol_RGDI1): Rolling variance of RGDI over X quarters $(X=3,4,6)$.

Volatility of real income (vol_RGDI2): Conditional variance of a cyclical part of gross disposable income, calculated using the Hodrick-Prescott filter, drawn from an $A R(n)-G A R C H(p, q)$, where $n, p$ and $q$ are natural numbers.

Volatility of real income (vol_RGDI3): Rolling variance of the ratio "cyclical part of RGDI (assessed using the Hodrick-Prescott, HP, filter) over RGDI" over $Z$ quarters ( $Z=3,4,6$ quarters).

Volatility of the riskiest asset (vol_CAC401): Conditional variance of the CAC40 returns drawn from an $A R(m)$ where $m$ is a natural number.

Volatility of the riskiest asset (vol_CAC402): Conditional variance of the cyclical part of CAC40 returns drawn from an $A R(m)$ where $m$ is a natural number.

\section{Business cycle components}

Deviation of the unemployment rate from its trend: Unemployment rate - its trend calculated using the HP filter.

Financial savings ratio: Financial savings (current prices) over GDI (current prices).

Deviation of the financial savings ratio: Financial savings ratio - its trend (calculated using the HP filter).

Real gross domestic product (RGDP); Real gross domestic product growth (GRGDP).

Relative "Output gap" (RGDP - its trend) /RGDP, the trend is calculated using the HP filter.

Gross disposable income (GDI), gross domestic product (GDP), financial savings and unemployment rate are drawn from INSEE datasets. The deflator is either the consumer price index (CPI) or the GDP deflator.

\section{Life cycle factors}

Population data are drawn from the INSEE dataset.

The high saver ratio is the ratio of the cohorts aged between 30 and 70 to total population. It corresponds to the proportion of households which display the highest savings rates. The 
The patterns displayed by the real $M 3 M 2$ and $P E L$ returns are quite similar and different from those of the other real returns (see Charts 2A and 2B): at the beginning of the sample, these two real returns were negative; they then increased until the end of the 1980s. From 1991 to 2013, they were on a downward trend. Due to very low inflation rates, a slight rebound appeared towards the end of the period. In contrast with the changes in real Lifebonds, M1 and M2MI returns, the real Assets return was unsurprisingly more volatile and displayed very large fluctuations (see Chart 2B). The dynamics of $M 1$ and $M 2 M 1$ real returns are very similar. After rather large fluctuations from the late 1970s to the early 1980s, real Lifebonds returns fluctuated weakly in a narrow range.

Chart 2A: Real returns of financial assets (in pp)

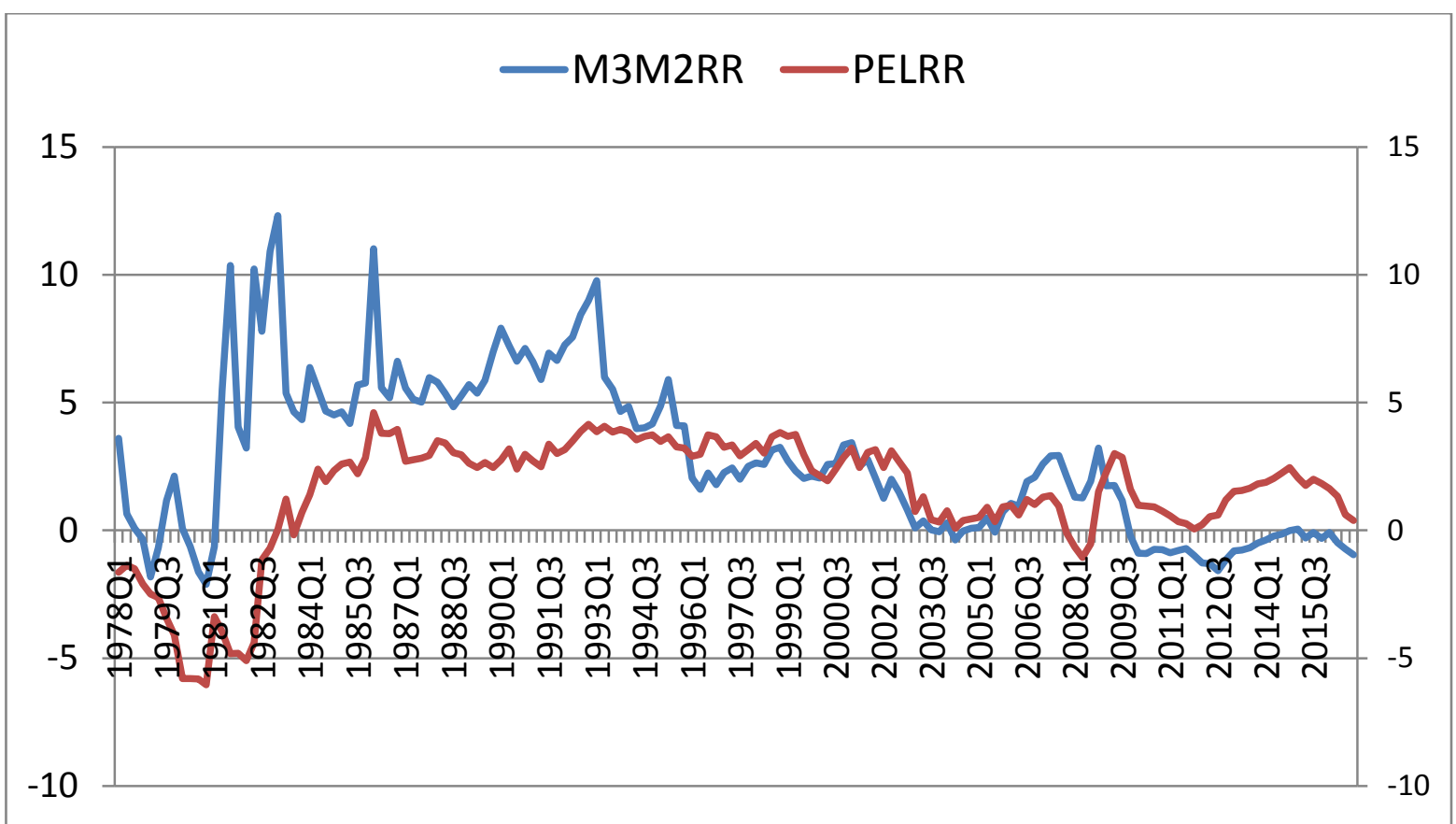

Chart 2B: Real returns of financial assets (continuation, in pp)

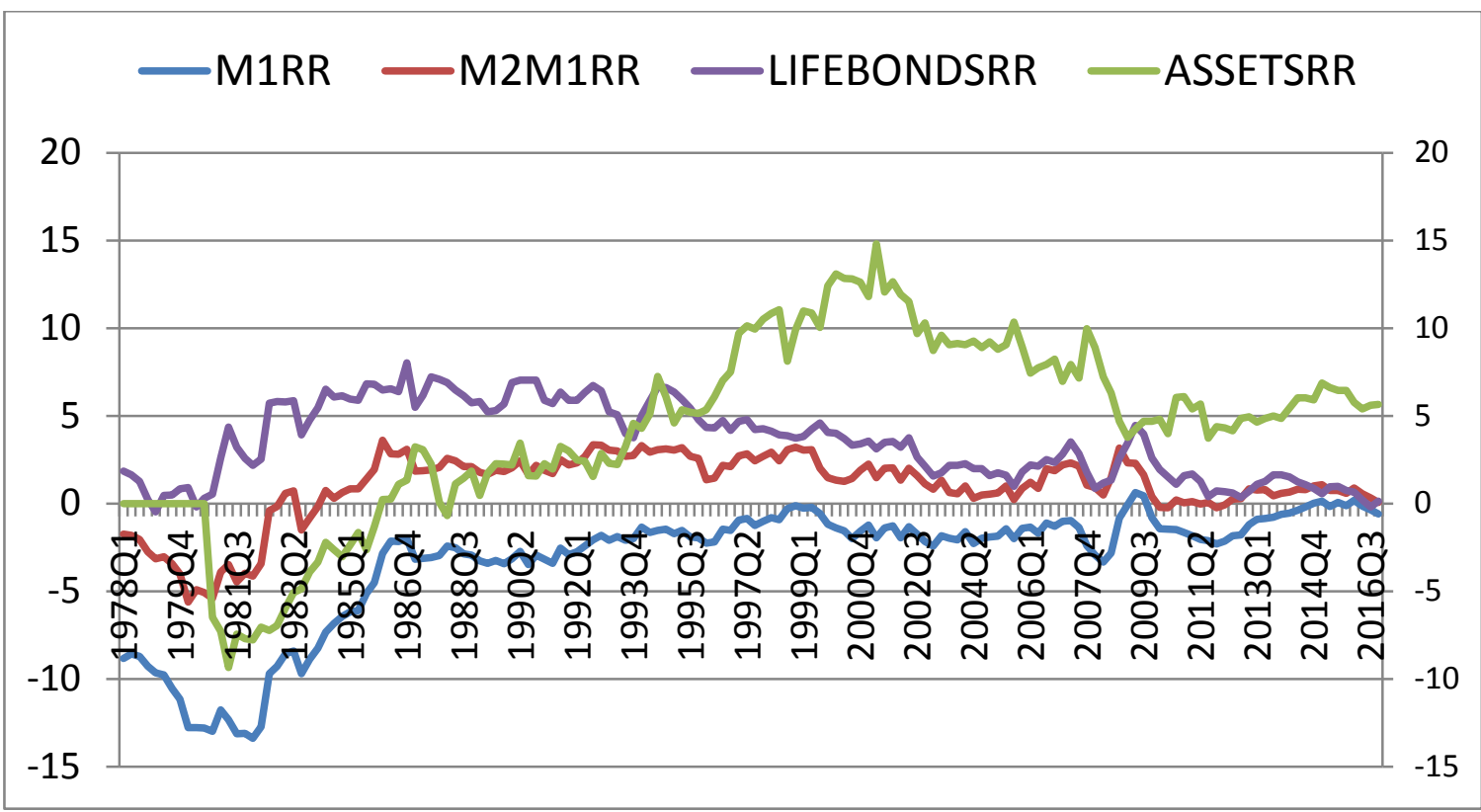

Sources: Banque de France and authors' calculations. 


\subsection{Detection of structural breaks}

\subsubsection{Bai-Perron tests}

According to the previous analysis, some shifts could affect the variations in shares. We apply the Bai-Perron tests, which enable us to detect multiple unknown breakpoints (Bai and Perron, 1998 and 2003) to data over the period from 1978 to 2016. These tests are run on the series of shares over the full sample (see Tables 1 and 2). We test two assumptions: i) the shifts are directly observed on the shares dynamics; ii) the shifts are checked through the univariate estimation of the previous equations of the shares (see Equation 7). In the latter case, the BaiPerron tests are run using the residuals of each single equation.

In the first case, we accept the hypothesis of the presence of many breakpoints in the shares as a whole. Indeed, the Bai-Perron tests exhibit four breakpoints for M1, M3M2, Assets and Lifebonds, and three for M2M1 and PEL (see Table 1). These breakpoints coincide more or less with the changes observed in the markets for these assets (changes in institutional or tax rules, etc.). It is interesting to note that there are no spurious breakpoints in the series: the results of the Bai-Perron tests are consistent with the evolutions of the shares presented above.

Besides, only M1 and M3M2 display a simultaneous shift in Q4 1996 (see Table 1, mean evaluation of the structural breaks). However, there are many shares which are impacted by a breakpoint in the same year (see for example: M1 and M3M2 in 1984 and 1989 or M2M1 and PEL in 1986 or M2M2, Assets and Lifebonds in 2008). Furthermore, a third breakpoint often appears at the end of the 1990s or in the early 2000s. Principally, for each share, a breakpoint is located around 1999, which coincides with the introduction of the euro.

Table 1: Screening of breakpoints in the shares based on the Bai Perron test (Q1 1978-Q4 2016)

\begin{tabular}{|c|c|c|c|c|c|c|c|c|c|c|c|c|}
\hline & \multicolumn{3}{|c|}{ Breakpoint 1} & \multicolumn{3}{|c|}{ Breakpoint 2} & \multicolumn{3}{|c|}{ Breakpoint 3} & \multicolumn{3}{|c|}{ Breakpoint 4} \\
\hline & $2.5 \%$ & Mean & $97.5 \%$ & $2.5 \%$ & Mean & $97.5 \%$ & $2.5 \%$ & Mean & $97.5 \%$ & $2.5 \%$ & Mean & $\begin{array}{c}97.5 \\
\%\end{array}$ \\
\hline & $\mathrm{Q}$ & & & Q2 & & Q1 & 4 & $Q$ & & V & Q3 & Q4 \\
\hline & 15 & 198 & & 19 & & & 1995 & 1996 & & 2002 & & 2003 \\
\hline$M 2 M 1$ & \begin{tabular}{|c} 
Q3 \\
1985
\end{tabular} & & & & & & $\begin{array}{c}\text { Q1 } \\
2008\end{array}$ & & & & & - \\
\hline JN & \begin{tabular}{|c} 
Q1 \\
1983
\end{tabular} & $\begin{array}{c}\text { Q4 } \\
1984\end{array}$ & $\begin{array}{c}\mathrm{Q} 4 \\
1985\end{array}$ & $\begin{array}{c}\mathrm{Q} 4 \\
1986\end{array}$ & & & \begin{tabular}{|c} 
Q3 \\
1995
\end{tabular} & $\begin{array}{c}Q 4 \\
1996\end{array}$ & & $\begin{array}{c}\text { Q2 } \\
2002\end{array}$ & $\begin{array}{c}\text { Q4 } \\
2003\end{array}$ & $\begin{array}{c}\text { Q3 } \\
2004\end{array}$ \\
\hline$P E L$ & $\begin{array}{c}\text { Q1 } \\
1986\end{array}$ & $\begin{array}{c}\text { Q3 } \\
1986\end{array}$ & $\begin{array}{c}\text { Q4 } \\
1987\end{array}$ & $\begin{array}{c}\text { Q2 } \\
1995\end{array}$ & & & $\begin{array}{c}\text { Q2 } \\
2006\end{array}$ & $\begin{array}{c}\text { Q3 } \\
2006\end{array}$ & & 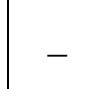 & - & \\
\hline Assets & $\begin{array}{c}\text { Q2 } \\
1985\end{array}$ & $\begin{array}{c}\text { Q3 } \\
1985\end{array}$ & $\begin{array}{c}\mathrm{Q} 4 \\
1986\end{array}$ & $\begin{array}{c}\text { Q2 } \\
1991\end{array}$ & $\begin{array}{c}\text { Q1 } \\
1992\end{array}$ & $\begin{array}{c}\text { Q4 } \\
1993\end{array}$ & $\begin{array}{c}\text { Q3 } \\
2001\end{array}$ & $\begin{array}{c}\text { Q1 } \\
2002\end{array}$ & $\begin{array}{c}\text { Q4 } \\
2003\end{array}$ & $\begin{array}{c}\text { Q2 } \\
2007\end{array}$ & $\begin{array}{c}\text { Q4 } \\
2008\end{array}$ & $\begin{array}{c}\text { Q2 } \\
2008\end{array}$ \\
\hline $\begin{array}{l}\text { Lifeb } \\
\text { onds }\end{array}$ & $\begin{array}{c}\text { Q2 } \\
1986\end{array}$ & $\begin{array}{c}\text { Q3 } \\
1987\end{array}$ & $\begin{array}{c}\text { Q4 } \\
1988\end{array}$ & $\begin{array}{c}\text { Q4 } \\
1993\end{array}$ & $\begin{array}{c}\text { Q1 } \\
1993\end{array}$ & $\begin{array}{c}\text { Q2 } \\
1993\end{array}$ & $\begin{array}{c}\text { Q2 } \\
1998\end{array}$ & $\begin{array}{c}\text { Q3 } \\
1998\end{array}$ & $\begin{array}{c}\text { Q3 } \\
1999\end{array}$ & $\begin{array}{c}\text { Q4 } \\
2007\end{array}$ & $\begin{array}{c}\text { Q1 } \\
2008\end{array}$ & $\begin{array}{c}\text { Q3 } \\
2008\end{array}$ \\
\hline
\end{tabular}

Source: Authors' estimations

Now, we assume that each share is explained by the baseline non-augmented model (without additional explanatory factors) but there is no dynamic interaction between any two of them. Due to the restrictions imposed by demand theory (Blake, 2004), the equation of the share of PEL is dropped from the framework (see Section 5). Thus, we do not explicitly estimate the equation describing this share and directly run the break test on the share of PEL. 
We apply the Bai-Perron test on the residuals of each of the five equations over the period from 1978 to 2016. Here, only one break affects each share (see Table 2, mean). For M1, Assets and Lifebonds, the breaks are detected in the second half of the 1990s. M3M2 and M2M1 display a break in 1993 (Q2) and 1994 (Q2). These results are broadly consistent with the previous ones. They suggest that the explanatory factors did not capture the breaks that occurred in the endogenous variables. Moreover, the choice of the breakpoint date can be guided by some economic or institutional considerations such as the introduction of the euro in 1999. The previous results of the tests are broadly consistent with these considerations.

Table 2: Screening of breakpoints in shares based on univariate equations (Q1 1978-Q4 2016)

\begin{tabular}{|l|l|l|l|}
\cline { 2 - 4 } \multicolumn{1}{c|}{} & \multicolumn{2}{c|}{ Breakpoints } & \multicolumn{2}{c|}{} \\
\cline { 2 - 4 } \multicolumn{1}{c|}{} & $2.50 \%$ & Mean & $97.50 \%$ \\
\hline M1 & Q4 1998 & Q1 1999 & Q4 1997 \\
\hline M2M1 & Q1 1994 & Q2 1994 & Q4 1993 \\
\hline M3M2 & Q1 1993 & Q2 1993 & Q4 1992 \\
\hline Assets & Q4 1995 & Q1 1996 & Q1 1995 \\
\hline Lifebonds & Q2 1995 & Q3 1995 & Q1 1995 \\
\hline
\end{tabular}

Source: Authors' estimations

\subsubsection{Lessons from rolling regressions}

In order to complete and confirm the revealed breaks, some rolling regressions were run over the period 1978-2016 to examine the joint variation in the shares, assuming that the unknown parameters of the dynamic system of shares are time-dependent. The rolling regressions at time $t$ are obtained through the estimation of all the coefficients over a window of 60 quarters and steps of 4 quarters.

The results of the estimations show that:

i) Whatever the equation, the hypothesis of time-dependency of the system's parameters is relevant (Appendix C);

ii) The parameters of the "core explanatory factors" and those of the "additional" explanatory variables display a similar behaviour. Overall, the first third part of the sample is associated with more volatile coefficients;

iii) The late 1990s and the early 2000s display a break in the coefficients. Indeed, most of the time, this period is associated with a shift in the trend of the coefficients: the coefficients show an upward or downward trend before stabilising in the following years;

iv) When the rolling regressions are run over the sub-sample preceding the 1990s, the picture is significantly different from that observed in the complementary sub-period (1990-2016).

Combining the results of the Bai-Perron tests and those of the rolling regressions enables us to assume that the sub-sample from the late 1990s to 2016 is quite stable.

\section{Empirical results}

\subsection{A brief overview of econometric methods}

Many econometric approaches have recently been developed to estimate the unknown parameters of general demand systems (Alston et al., 1994, Ozuna, 1994, Pashardes, 1993, ...). Furthermore, as these systems are often highly non-linear with non-null correlations between the residuals, the econometric methods applied in this area are complex. 
Bayesian inference is one of the promising avenues in this research field since it provides additional information (prior distributions of the unknown parameters, etc.). Bayesian approaches also help circumvent some identification problems. However, finding appropriate prior distributions can be problematic and the empirical results of the estimates could be biased if the prior distributions are not relevant. Finally, in some cases, the unknown parameters are calibrated (Moschini, 1995).

Besides, the results based on different econometric methods are also sometimes contradictory. Chua et al. (2001) found that the estimates based on the Bayesian method and those obtained with the Maximum Likelihood Estimators (MLE) are quasi similar. However, according to Kabe and Kanazawa (2014), Bayesian estimation prevails over MLE in terms of mean square errors.

Due to uncertainties surrounding the Bayesian approach, and as we have no preconceived ideas on the initial values (prior distributions, initial points, etc.) of the main parameters, we do not implement the Bayesian inferences in this paper.

For empirical purposes (correlations between the residuals and the exogenous variables, etc.), we use instrumental variables methods to estimate the unknown parameters of the model. Following Blake (2004), we implement the conventional three-stage least squares (3SLS) estimation.

The choice of the instruments is based on the common view in this research area (Blake, 2004). To be more precise, the set of instruments contains the first four order lagged values of the endogenous variables and the current and first four order lagged values of the weakly exogenous factors. We do not introduce the dummy variables in our set of instruments.

Taking into account the presence of some breaks in the endogenous dynamics, the estimation starting date is the first quarter of 1999. Thus, the baseline model is estimated over the more homogeneous period which spans from Q1 1999 to Q4 2016. In addition, adding-up conditions requirements are imposed in all the estimations (see below). Finally, estimates and diagnostic tests are provided by the Windows-based econometric software Eviews 10.

\subsection{Estimates of the baseline model}

\subsubsection{Estimation results}

The baseline model is the dynamic system of equations (see Equation 8) with two exogenous variables (uncertainty or risk factor and demographic factor)and is a Stone index-based model. The set of instruments variables contains the lagged values of the endogenous and exogenous variables.

\subsubsection{Unconstrained model with two exogenous factors}

In order to meet adding-up conditions requirements (imposed by demand theory, Blake, 2004), we drop one equation (the share of PEL, see Section 4) from the dynamics system and infer its parameters from the restrictions conditions (see Box 1). The relative weakness of the weight of the share of PEL explains the choice of this share as a "residual".

Following Blake (2004), we reassess the elasticities corresponding to wealth, interest rates and additional exogenous factors. The Student-t statistics shown in the tables are heteroscedasticity and auto-correlation consistent (see below, figures in brackets). The conventional validation tests (Wald, ADF, autocorrelation, normality, Arch, etc.) are also conducted and displayed in the tables of results. 
Before examining the empirical results of the baseline model, we question the relevance of the demand theory restrictive conditions (adding-up conditions requirements). To do so, we examine the preliminary results based on an unconstrained model. We estimate the previous dynamic system by skipping the homogeneity and symmetry assumptions and imposing two exogenous factors in the regressions. The results of this preliminary estimation are displayed in Table 3: the statistics and p-values of the tests regarding the hypotheses of homogeneity and symmetry are shown in Table $3 \mathrm{~A}$; Table $3 \mathrm{~B}$ is devoted to the uncompensated interest rates elasticities $^{6}$.

As regards the adding-up conditions, at the conventional levels, we cannot reject the homogeneity and symmetry assumptions (see Table 3A). Indeed, we strongly accepted these assumptions by considering them individually or jointly (the p-values are larger than 0.80 whatever the hypothesis). As a result, if we do not take them under consideration in the analytical framework, the estimated parameters will almost surely be biased.

Nevertheless, even if the estimated parameters are surely biased, these preliminary results are in line with economic intuition. In particular, the effects of real interest rates on the shares are those expected. In addition, the results suggest the presence of substitution effects (negative coefficients) and complementarity effects (positive coefficients) between the shares through real interest rates. For instance, a substitution effect could arise between the shares M1M2 and M3M2 or Assets and Lifebonds whereas a complementarity effect could prevail between the shares M3M2 and Lifebonds or M2M1 and Assets. These results need to be confirmed by more robust estimations.

Nevertheless, the estimates shown in Table 3B (and Appendix D, Table D1) impose the hypotheses of homogeneity and symmetry. These assumptions condition the validity of the results. In other words, the estimation of the baseline model takes into account the adding-up conditions.

Table 3A: Tests of restrictions implied by demand theory

(Unconstrained model with two exogenous factors, Wald test statistics (long run))

\begin{tabular}{|l|l|l|l|}
\cline { 2 - 4 } \multicolumn{1}{c|}{} & Theoretical & Empirical & P-values at 5\% \\
\hline Homogeneity $\left(\chi^{2}(5)\right)$ & 11.07 & 1.15 & 0.95 \\
\hline Symmetry $\left(\chi^{2}(10)\right)$ & 18.31 & 6.19 & 0.80 \\
\hline Homogeneity and symmetry & 25.00 & 8.45 & 0.90 \\
\hline
\end{tabular}

Table 3B: Uncompensated Interest rate elasticities

(Unconstrained model with two exogenous factors)

\begin{tabular}{|l|c|c|c|c|c|c|}
\cline { 2 - 7 } \multicolumn{1}{c|}{} & M1 & M2M1 & M3M2 & PEL & Assets & Lifebonds \\
\hline M1 real rate & 4.8 & -6.1 & -1.6 & -5.8 & -0.8 & 9.5 \\
\hline M2 real rate & 0.3 & 10.7 & -2.8 & 34.2 & 6.8 & -49.2 \\
\hline M3 real rate & 0.4 & -6.7 & 3.6 & -15.8 & 1.3 & 17.1 \\
\hline Pel real rate & -1.8 & 0.1 & 1.6 & -10.6 & -1.9 & 12.7 \\
\hline Assets real rate & -0.2 & 0.0 & -1.2 & 7.4 & 4.8 & -10.8 \\
\hline Lifebonds real rate & -6.0 & 1.5 & -0.5 & -1.9 & -7.9 & 14.8 \\
\hline
\end{tabular}

\footnotetext{
${ }^{6}$ The results regarding the shares equations are presented in Appendix D (Table D1).
} 


\subsubsection{Constrained model with two exogenous factors}

According to the preliminary results, we introduce homogeneity and symmetry assumptions in the following estimation of the baseline model. The regressions are run over the period 19992016. In view of the fact that we will perform additional tests later, we only display the estimates of uncompensated return elasticities in Table 4 below (see Appendix D, Table D2 for the full results).

The empirical results highlight the effect of the changes in returns on the shares of financial assets (see Table 4). Overall, the share of each financial asset is significantly and positively impacted by its own return but also by those of the other shares. In this last case, the effects depend on financial assets, and are either positive (complementarity effect) or negative (substitution effect). For instance, the return on M1 negatively influences the variations in Lifebonds, whereas the return on M2M1 seems positively correlated with the share of Assets.

As mentioned before, unlike in the case of the unconstrained model, the elasticity of the own interest rate of each financial share has the expected sign. When the own return on a financial asset then rises, all things being equal, the weight of this asset in the financial wealth increases. On this basis, the estimates of the main coefficients of the constrained model are in line with the economic intuition.

Moreover, moving from the unconstrained to the constrained model leads to changes in the estimated coefficients (magnitude and/or sign). Indeed, we notice some significant differences between the estimated parameters of the two models: the estimated coefficients of the constrained model are sometimes larger than those of the unconstrained model (see the coefficient of M1 real rate in M1 equation, or those of M2 real rate and M3 real rate in M2M1 and M3M2 equations), and sometimes weaker (see the coefficient of Lifebonds real rate in the Lifebonds equation). However, some broad similarities appear between the estimates displayed in Tables 3B and 4.

It is worth mentioning that some parameters of the system of equations are calibrated (see Appendix Table D2). We also need to test the relevance of the assumption of an identical autoregressive process across the five estimated equations of the system.

As regards the two exogenous factors introduced in the regressions, it is worth noting that they were selected on the basis of the significance of their contributions to the dynamics of the endogenous variables. In addition, we tested the effects of many risk factors (volatility of real income, etc., see Box 2) in our preliminary regressions. We obtained the best performances with the volatility of the riskiest asset (market volatility in the previous and following regressions).

We also introduced some components of business cycle indicators (financial savings ratio, output gap, etc., see Box 2) and various indicators of the life cycle in our regressions. Unfortunately, we did not obtain any meaningful results (in terms of the contributions of these factors to the changes in the shares) with these factors, except for the de-trended unemployment rate (as a business cycle indicator). For example, the high saver ratio that might impact the shares of Assets or Lifebonds has a marginal effect on the system of shares. 
Table 4: Uncompensated elasticities

(Constrained model - homogeneity and symmetry - two exogenous factors)

\begin{tabular}{|l|c|c|c|c|c|c|}
\cline { 2 - 7 } \multicolumn{1}{c|}{} & M1 & M2M1 & M3M2 & PEL & Assets & Lifebonds \\
\hline M1 real rate & 6.3 & -0.5 & -0.1 & -2.3 & 0.5 & -3.8 \\
\hline M2 real rate & -0.5 & 13.7 & -5.7 & -2.7 & 1.6 & -6.4 \\
\hline M3 real rate & -0.1 & -5.7 & 4.0 & 1.0 & -1.0 & 1.8 \\
\hline Pel real rate & -2.3 & -2.7 & 1.0 & 1.7 & 0.0 & 2.2 \\
\hline Assets real rate & 0.5 & 1.6 & -1.0 & 0.0 & 1.0 & -2.2 \\
\hline Lifebonds real rate & -3.8 & -6.4 & 1.8 & 2.2 & -2.2 & 8.5 \\
\hline
\end{tabular}

\subsubsection{The baseline model: constrained model with two exogenous factors}

Due to the scarcity of the data, we test an additional constraint which consists in defining the same autoregressive process across the five equations. We cannot reject the null hypothesis for the unconstrained and constrained models at the $5 \%$ level (see Table 5A). Overall, the null hypothesis is increasingly well accepted as the order of the auto regressive process rises. In other words, the introduction of the additional hypothesis regarding the autoregressive process should not undermine the performances of the system of equations describing the shares of financial assets under review in this paper.

Table 5A: Tests of restrictions on the AR process (Wald Test statistics, long run)

\begin{tabular}{|l|c|c|c|}
\cline { 2 - 4 } \multicolumn{1}{c|}{} & $\begin{array}{c}\text { Theoretical } \\
\text { statistics at 5\% }\end{array}$ & $\begin{array}{c}\text { Empirical } \\
\text { statistics }\end{array}$ & P-values at 5\% \\
\hline $\begin{array}{l}\text { Unconstrained model }\left(\chi^{2}\right. \\
(35))\end{array}$ & 49.80 & 49.22 & 0.06 \\
\hline $\begin{array}{l}\text { Constrained model (symmetry } \\
\text { and homogeneity) }\left(\chi^{2}(3)\right)\end{array}$ & 7.81 & 3.03 & 0.38 \\
\hline $\begin{array}{l}\text { Constrained model (symmetry, } \\
\text { homogeneity and stability) }\left(\chi^{2}\right.\end{array}$ & 31,41 & 19.10 & 0.52 \\
\hline
\end{tabular}

As a consequence, we are inclined to adopt a system based on the identical autoregressive process across the five equations combined with the adding-up assumptions and the introduction of two exogenous factors. These assumptions and the set of equations of the shares constitute the baseline framework of our empirical analysis.

Table 5B displays the results of the estimates of the coefficients of the fully constrained model with two exogenous variables. As regards the effects of the interest rates, we note that each asset is significantly and positively correlated with its own return. In the end all things being equal, an increase in the real return on asset " $\mathrm{i}$ " ( $\mathrm{i}=\mathrm{M} 1, \mathrm{M} 2 \mathrm{M} 1, \ldots$, Lifebonds) leads to a rise in asset "i $\mathrm{i}$ ". The sensitivity of the share to the real return depends on the asset, with the reactions of M1, M2M1 and Lifebonds to their own real returns being stronger than those of M3M2, Asset and PEL. However, whatever the asset, the uncompensated elasticity is significantly different from zero. One can also note cross-effects between real returns and financial assets. Overall, the real interest rate of M1 predominantly impacts the other shares negatively; in this case, a substitution effect prevails. A similar pattern exists regarding the effect of the real interest rate of M2 on the other shares. In fact, substitution effects prevail overall.

As regards wealth elasticity, the empirical results bring to light three situations. In the first case, there is a strong positive effect of wealth on Lifebonds. Only the richer households seem to react to the variations in Lifebonds. In the second case, we note a negative link between some financial assets (M1, M3M2) and wealth. According to Blake (2004), these assets are wealthinferior assets with a long run negative elasticity. It is worth noting that these assets are relatively liquid. Perhaps the changes in wealth are offset by the opposite variations in these 
liquid assets. In the last case, we note a weak correlation between two assets (M2M1 and Assets) and wealth as their coefficients in the corresponding regressions are not significantly different from 0. In particular, Assets seem to be substantially driven by their own returns and the substitution effects induced by Lifebonds.

Finally, only M1 is significantly correlated with the business cycle (through the de-trended unemployment rate) and financial uncertainty (via financial market volatility). Unexpectedly, as mentioned before, the other shares, especially the Assets one, are not statistically impacted by real or financial risk factors.

Some validation tests statistics are also shown in Table 5B. In general, according to the adjusted $\mathrm{R}^{2}$ statistic, the model fits the data well. Indeed, except for $\mathrm{M} 1$, the adjusted $\mathrm{R}^{2}$ for the different regressions are higher than 0.60 . In particular, for the most important share (Lifebonds), the adjusted $\mathrm{R}^{2}$ is close to 0.80 . These performances are fairly good. As expected, the stationary tests lead to the rejection of the presence of a unit root. However, in the current estimation, it is not possible to reject the assumption of the presence of auto-correlation in the residuals. In order to be in line with applied econometrics and obtain non-biased results, the residuals should be whitened or the standard errors and t-statistics should be corrected for auto-correlation and heteroscedasticity. We choose the second option by correcting the statistics for the two assumptions. In this way, the confidence intervals of the parameters shown in the tables are unbiased and can be feasibly interpreted.

Table 5B: Estimates of the coefficients of the baseline model

(Constrained model - homogeneity / symmetry / stable AR - two exogenous factors)

\begin{tabular}{|c|c|c|c|c|c|c|}
\hline & M1 & M2M1 & M3M2 & PEL & \multicolumn{2}{|c|}{ Assets Lifebonds } \\
\hline Wealth elasticity & $\begin{array}{c}-0.1 \\
(-4.3) \\
\end{array}$ & $\begin{array}{c}0.0 \\
(-0.8) \\
\end{array}$ & $\begin{array}{c}-0.1 \\
(-2.6) \\
\end{array}$ & $\begin{array}{c}0.0 \\
-\end{array}$ & $\begin{array}{c}-0.0 \\
(-1.2) \\
\end{array}$ & $\begin{array}{c}0.2 \\
(7.9)\end{array}$ \\
\hline Uncompensated interest rates & & & & & & \\
\hline M1 real rate & $\begin{array}{c}6.0 \\
(7.9)\end{array}$ & $\begin{array}{l}-1.5 \\
-\end{array}$ & $\begin{array}{c}0.3 \\
-\end{array}$ & $\begin{array}{c}-1.5 \\
-\end{array}$ & $\begin{array}{c}-0.2 \\
-\end{array}$ & $\begin{array}{c}-3.0 \\
-\end{array}$ \\
\hline M2 real rate & $\begin{array}{l}-1.5 \\
(-2.1)\end{array}$ & $\begin{array}{c}5.4 \\
(5.6)\end{array}$ & $\begin{array}{c}-2.7 \\
-\end{array}$ & $\begin{array}{c}-0.0 \\
-\end{array}$ & $\begin{array}{c}-1.3 \\
-\end{array}$ & $\begin{array}{c}0.1 \\
-\end{array}$ \\
\hline M3 real rate & $\begin{array}{c}0.3 \\
(0.6) \\
\end{array}$ & $\begin{array}{c}-2.7 \\
(-5.0) \\
\end{array}$ & $\begin{array}{c}2.6 \\
(3.5) \\
\end{array}$ & $\begin{array}{c}-0.0 \\
- \\
\end{array}$ & $\begin{array}{c}-0.9 \\
- \\
\end{array}$ & $\begin{array}{c}0.8 \\
-\end{array}$ \\
\hline Pel real rate & $\begin{array}{c}-1.5 \\
-\end{array}$ & $\begin{array}{c}-0.0 \\
-\end{array}$ & $\begin{array}{c}-0.0 \\
-\end{array}$ & $\begin{array}{c}0.5 \\
-\end{array}$ & $\begin{array}{c}1.4 \\
-\end{array}$ & $\begin{array}{c}-0.3 \\
-\end{array}$ \\
\hline Assets real rate & $\begin{array}{c}-0.2 \\
(-0.6) \\
\end{array}$ & $\begin{array}{c}-1.3 \\
(-3.3)\end{array}$ & $\begin{array}{c}-0.9 \\
(-2.0) \\
\end{array}$ & 1.4 & $\begin{array}{c}3.3 \\
(4.2) \\
\end{array}$ & $\begin{array}{c}-2.3 \\
- \\
\end{array}$ \\
\hline Lifebonds real rate & $\begin{array}{l}-3.0 \\
(-6.5) \\
\end{array}$ & $\begin{array}{c}0.1 \\
(0.1)\end{array}$ & $\begin{array}{c}0.8 \\
(1.1)\end{array}$ & $\begin{array}{c}-0.3 \\
-\end{array}$ & $\begin{array}{c}-2.3 \\
(-3.5) \\
\end{array}$ & $\begin{array}{c}4.8 \\
(5.1) \\
\end{array}$ \\
\hline $\begin{array}{l}\text { Detrended unemployment } \\
\text { rate }\end{array}$ & $\begin{array}{c}-0.8 \\
(-2.9)\end{array}$ & $\begin{array}{c}0.4 \\
(0.9)\end{array}$ & $\begin{array}{l}-0.4 \\
(-0.7)\end{array}$ & $\begin{array}{c}0.0 \\
-\end{array}$ & $\begin{array}{c}-0.6 \\
(-0.6)\end{array}$ & $\begin{array}{c}0.5 \\
(0.6)\end{array}$ \\
\hline Financial market volatility & $\begin{array}{c}0.0 \\
(2.8) \\
\end{array}$ & $\begin{array}{c}-0.0 \\
(-0.0) \\
\end{array}$ & $\begin{array}{c}-0.0 \\
(-0.4)\end{array}$ & $\begin{array}{c}0.0 \\
-\end{array}$ & $\begin{array}{c}0.0 \\
(0.1)\end{array}$ & $\begin{array}{c}0.0 \\
(0.3)\end{array}$ \\
\hline
\end{tabular}

Validation Tests

\begin{tabular}{|l|c|c|c|c|c|c|}
\hline Adjusted $\mathrm{R}^{2}$ & 0.12 & 0.78 & 0.68 & - & 0.60 & 0.78 \\
\hline $\mathrm{DW}$ & 2.24 & 1.51 & 1.60 & - & 1.76 & 1.88 \\
\hline Normality $\chi^{2}(2,5.99)$ & 3.93 & 2.81 & 1.77 & - & 4.40 & 2.64 \\
$(P$ value 5\%) & 0.14 & 0.25 & 0.41 & - & 0.11 & 0.27 \\
\hline ADF test $(1,-2.88)$ & -9.87 & -6.73 & -6.72 & - & -7.45 & -7.95 \\
\hline Autocorrelation $\chi^{2}(3,7.81)$ & 13.85 & 33.43 & 16.86 & - & 34.79 & 30.00 \\
$(P$ value 5\%) & 0.00 & 0.00 & 0.00 & - & 0.00 & 0.00 \\
\hline Arch $\chi^{2}(3,7.81)$ & 1.27 & 6.37 & 10.07 & - & 2.16 & 2.41 \\
$(P$ value 5\%) & 0.74 & 0.10 & 0.02 & - & 0.54 & 0.49 \\
\hline
\end{tabular}




\subsubsection{What are the main factors driving portfolio allocation?}

In this section, using the results shown in Table 5B, we assess the contributions of each exogenous factor to the changes in the shares.

Being in line with the analysis above, and as shown by the patterns of the contributions displayed in Chart 3A, the real return on M1 makes the most noticeable contribution to the changes in M1, and the real returns of other shares also contribute to the variations in M1. Finally, other factors (wealth, business cycle indicator, financial market risk factor) have a slightly weak impact on the dynamics of M1.

Chart 3A: Contribution of the explanatory factors to the change in M1 (Percentage point)

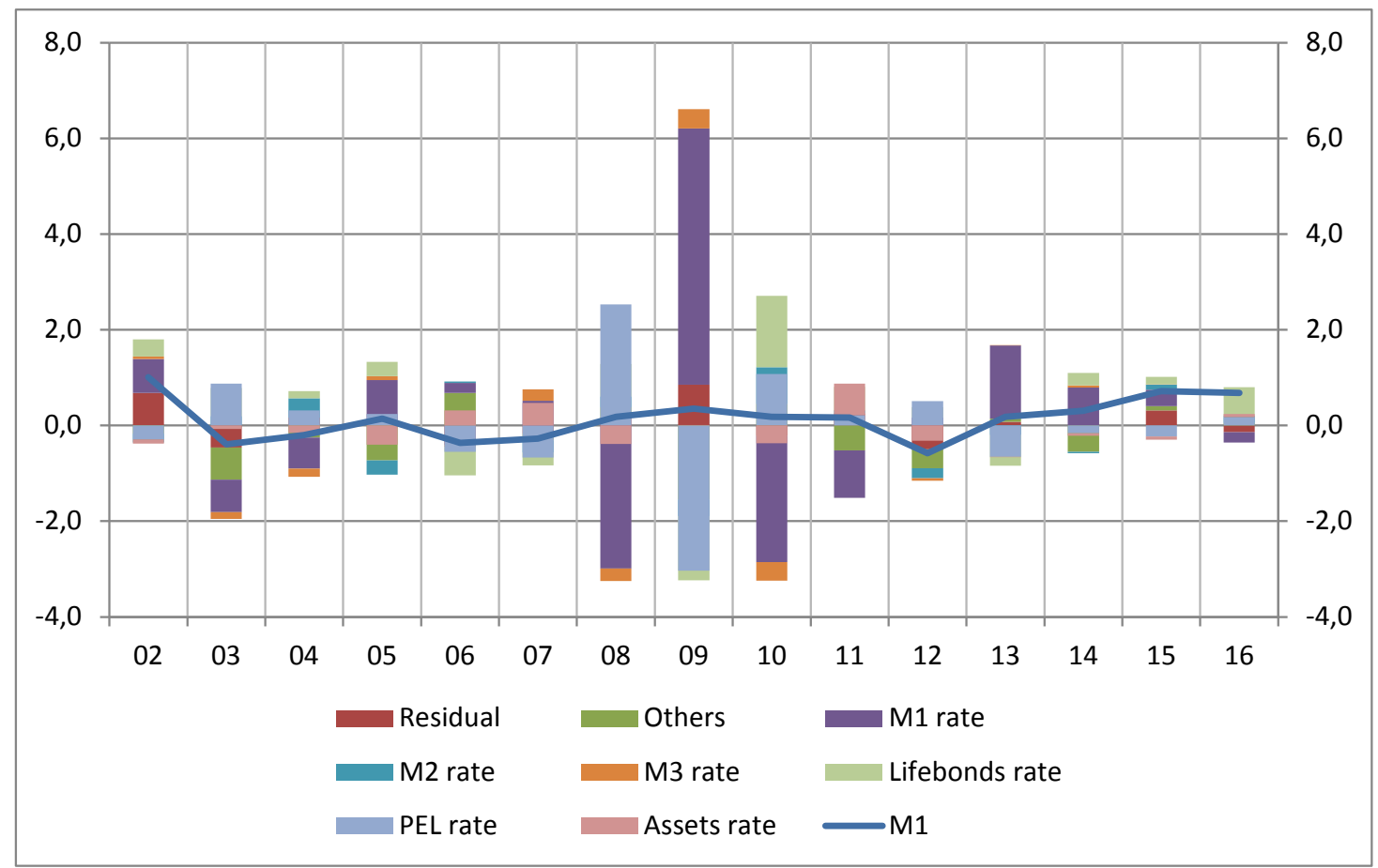

As regards the share M2M1, the outcome is slightly different (see Chart 3B). Obviously, the real rate of return on M2M1 plays a key role in its dynamics but the contributions of other real returns are also noticeable. For example, the real return on M3M2 significantly contributes to the changes in M2, whereas the impact of the real return on M1 on M2M1 is particularly visible during the last global financial crisis. Contrary to the previous case, the residual plays a nonnegligible role in the dynamics of M2M1.

Now, as regards the patterns of the contributions of the main factors explaining the dynamics of M3M2 (see Chart 3C), we notice the following: a strong prevalence of the contribution of the real return on M3M2 throughout the period under review; a relative persistence of the effect of the real return on Assets, especially in the first part of the period; a non-negligible impact of other factors (wealth, business cycle indicator, financial market risk factor) on the dynamics of M3M2 from the beginning to the end of the period under review. The residual of the regression has increasingly contributed to the variations in M3, especially since the financial crisis. This result could be linked to transitory changes in households' behaviour that are not taken into account by the explanatory factors. Finally, despite the large amplitude observed in the variations in the share M3, the model replicates its dynamics well. 
The outcome regarding the Assets share is quite different (see Chart 3D). Indeed, there is no clear predominance of one factor over the others in terms of the magnitude of the contribution: the real return on Assets predominates throughout the period but its contributions are solely noticeable over the first half of the period under review. The real interest rates of PEL, M3M2 and, to a lesser extent, Lifebonds strongly contribute to the changes in Assets but their contributions are not permanently significant. Finally, the contribution of the residual is really discernible in the second half of the period. Concerning other assets, there are regular adverse effects of the different explanatory variables.

Chart 3B: Contribution of the explanatory factors to the change in M2M1 (Percentage point)

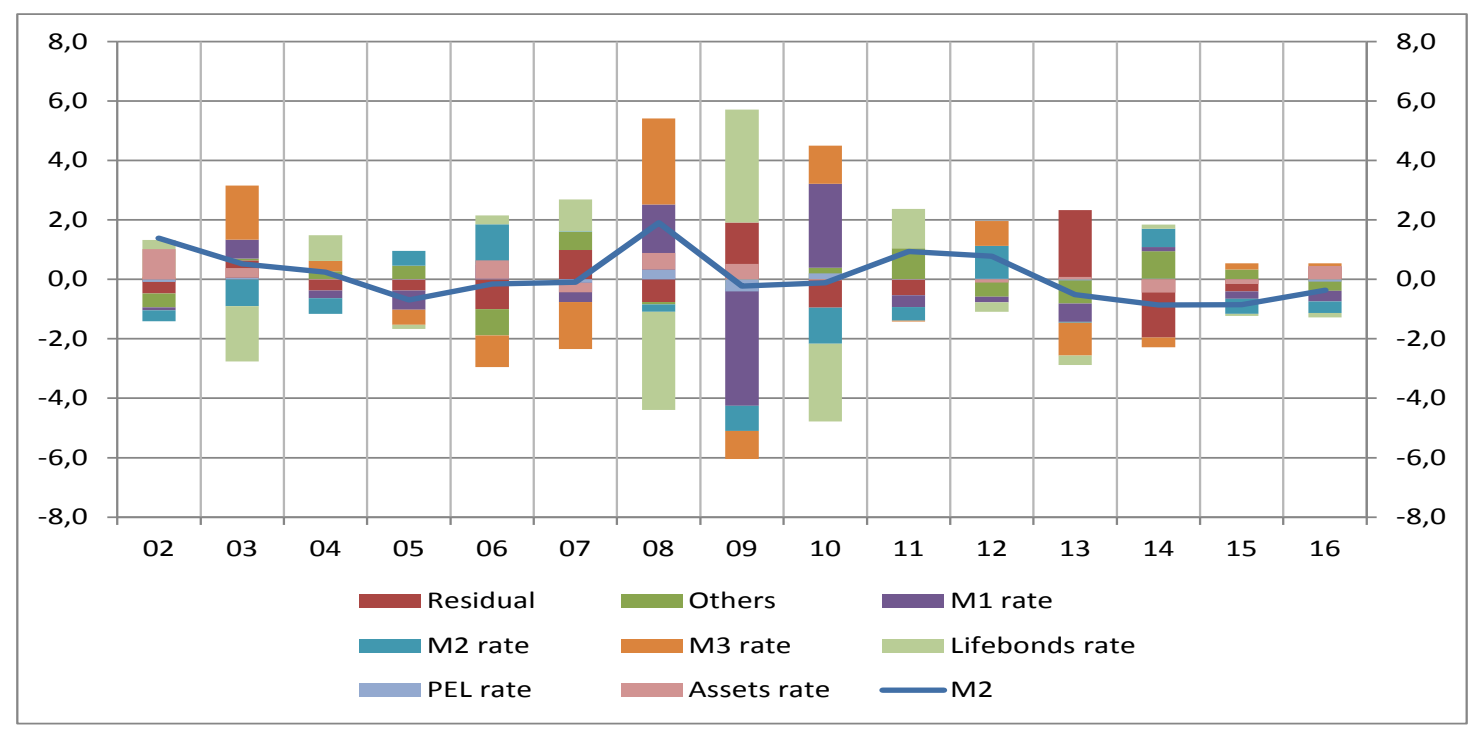

Chart 3C: Contribution of the explanatory factors to the change in M3M2 (Percentage point)

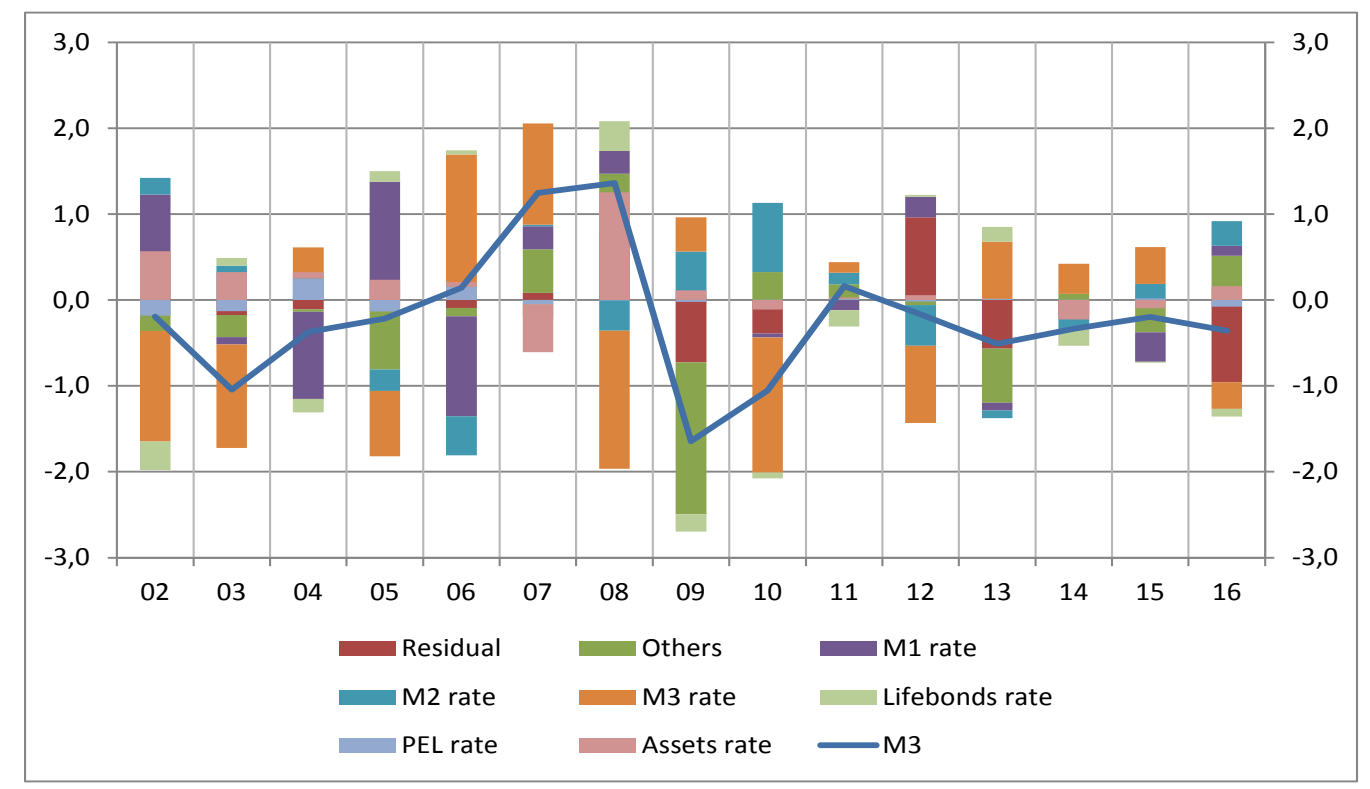

Finally, as regards Lifebonds, the influence of its own real return is almost negligible throughout the period under review (see Chart 3E). Here again, the combined effects of real returns on Lifebonds are at play. For example, over the sub-period corresponding to the global financial crisis (2008-2010), the dynamics of Lifebonds are essentially driven by the most short- 
term or liquid financial assets (M1, M2M1) and the most long-term or riskiest assets (Assets, Lifebonds). Furthermore, the largest contributions of the real return on Lifebonds are observed over this sub-period. However, the residual plays a marginal role in the development of the share of Lifebonds.

Chart 3D: Contribution of the explanatory factors to the change in Assets (Percentage point)

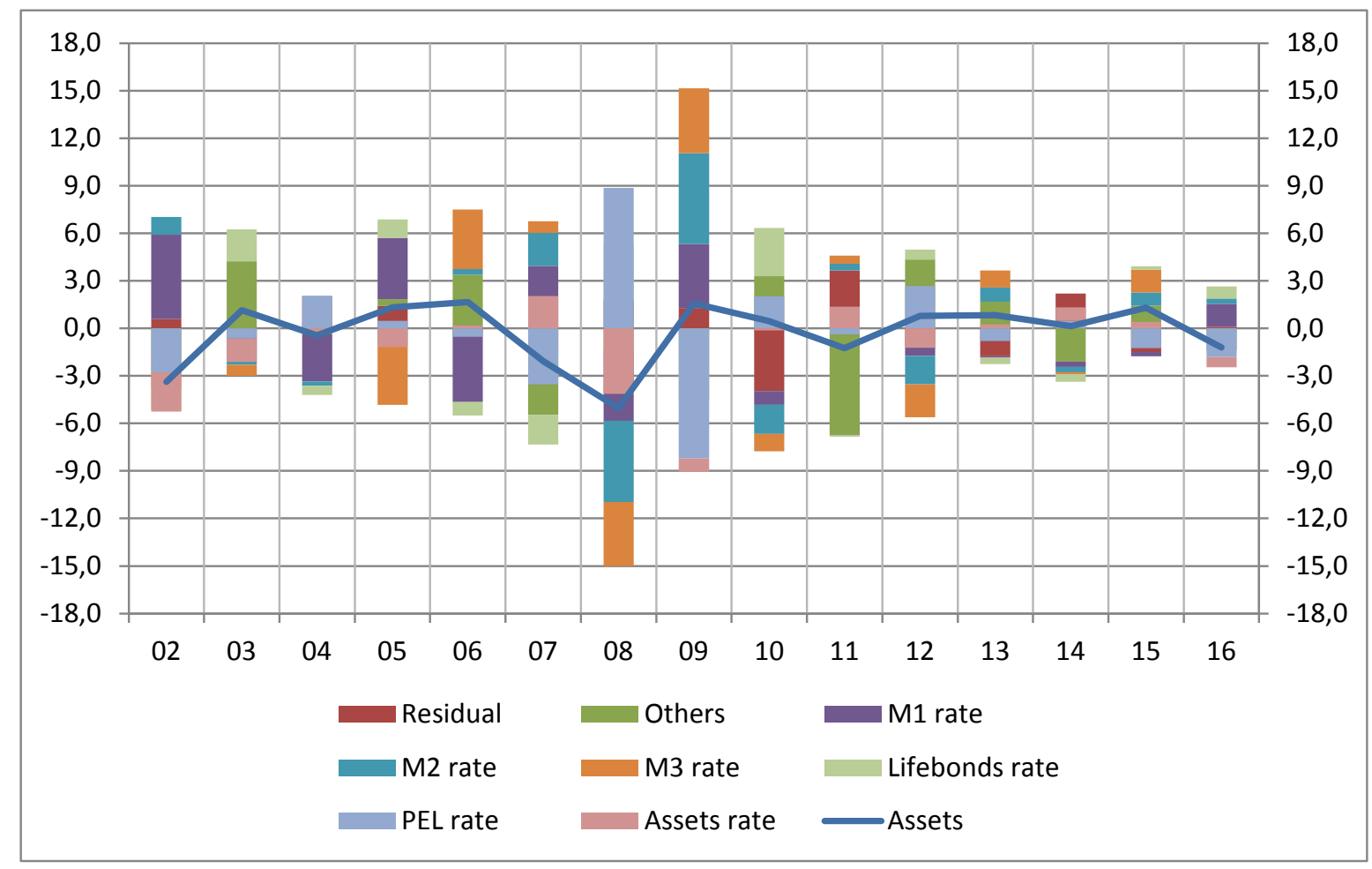

Chart 3E: Contribution of the explanatory factors to the change in Lifebonds (Percentage point)

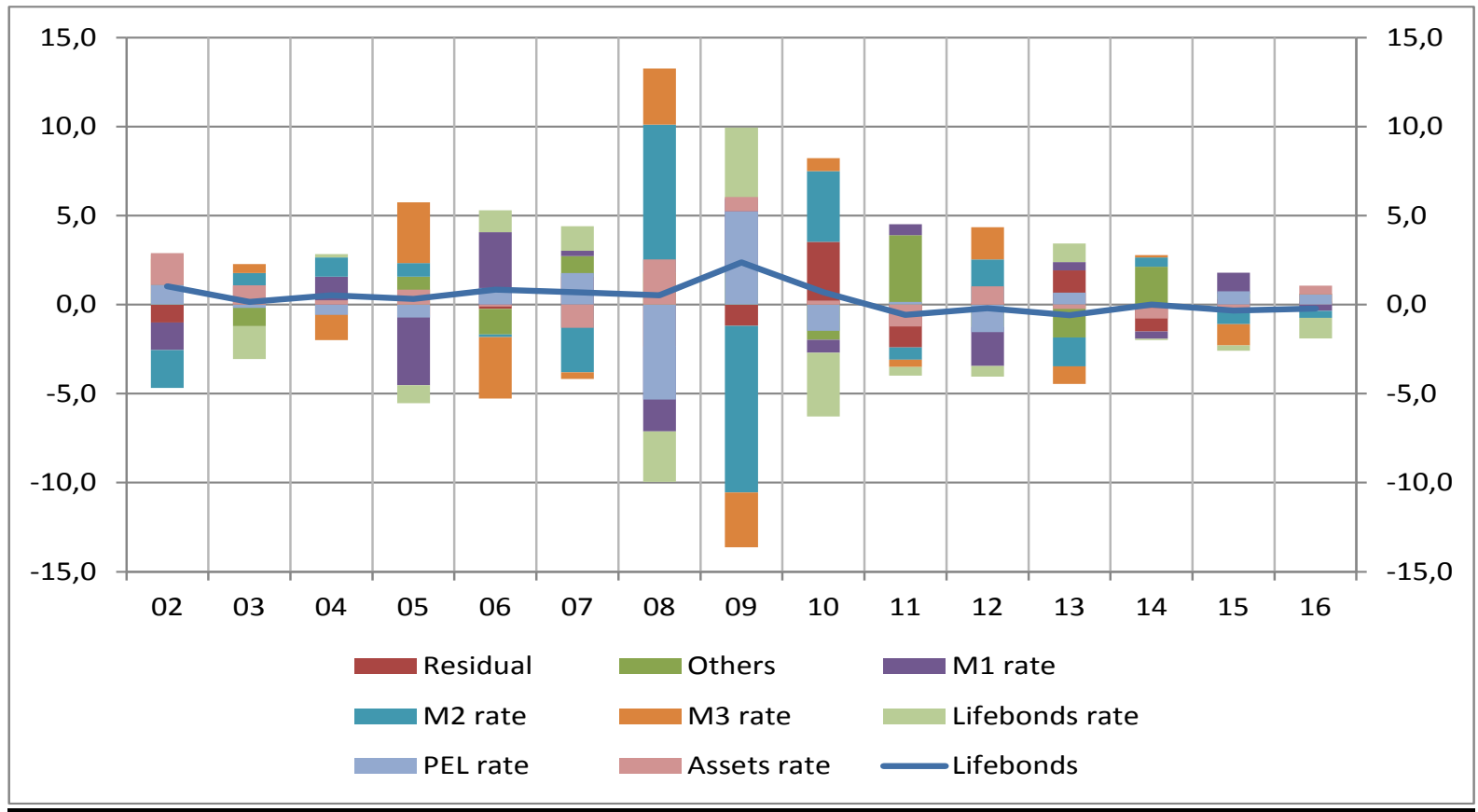




\section{Robustness checks}

We perform some sensitivity analyses of the estimation in order to assess how the empirical results could be impacted by changes in the hypotheses that drive the benchmark model. Robustness checks are conducted with respect to the three following assumptions:

1) Dropping exogenous variables from the baseline framework;

2) Replacing the regression of PEL by that of M3M2 as the residual regression;

3) Changing the structure of the lags of the weights in the baseline model.

All the models are estimated using the 3SLS method over the period 1999-2016. The estimations of the models are performed under the same assumptions as those imposed in the estimation of the baseline model. The empirical results shown below can thus be directly compared to those associated with the baseline model (see Table 5B).

\subsection{The baseline model without exogenous variables}

Our objective is to check the economic and statistical relevance of the presence of two exogenous factors in the dynamic system of the financial portfolio allocation. In this section, we thus remove the business cycle indicator and the financial market risk factor that were introduced in the baseline framework. Therefore, in this reduced model, only the parameters of the real interest rates and wealth factor are estimated and shown in Table 6.

When we compare the wealth elasticities in Table 5B and Table 6, we do not observe any significant difference between the outcomes: the estimated coefficients are broadly identical. The elasticity of M2 relative to Wealth is negligible but significantly different from 0 in the reduced model, whereas it is null in the benchmark model. As regards the uncompensated interest rates elasticity, the following remarks can be made:

i) Overall, the estimated parameters are qualitatively similar (they are either positive or negative in both models). From this point of view, the results confirm the relative relevance of the set of exogenous factors;

ii) There are some differences related to the magnitude or the significance of the coefficients between the outcomes in the two models. The effects of real return "i" in the equation of asset " $i$ " display contrasted pictures. Overall, the coefficients obtained in the reduced model are larger than those in the benchmark model, with the exception of the coefficient of the real return on M1 in the equation of the M1 share. Indeed, the parameter of the real return on M1 is significantly higher in the baseline model (6.0 versus 3.4). The reverse situation is observed for the M2M1 and M3M2 shares. The estimated coefficients of real returns for the Assets and Lifebonds shares are quasi identical in both models (for the share Assets, 3.6 in the reduced model versus 3.3; for Lifebonds, 4.9 for the reduced model versus 4.8 );

iii) The cross-effects (effect of the return on asset $i$ on the dynamics of asset $j$ with $i$ different from $\mathrm{j}$ ) estimated in the two models are quite different. They depend on the specifications. For example, the real return on M3 does not significantly impact M1 in the baseline model, whereas it does in the reduced model. Also, the coefficient of the real return on Lifebonds in the benchmark model is significantly higher than the one in the reduced model. There is more or less the same observation for the M2 real interest rate;

iv) The validation tests lead to similar conclusions for both the reduced and benchmark models. However, the adjusted $\mathrm{R}^{2}$ regarding M1 is significantly higher in the reduced model ( 0.58 versus 0.12$)$.

The gain obtained through the introduction of the two exogenous factors is marginal. However, taking these factors into account enables us to integrate two empirically founded dimensions into the dynamics of the determination of the financial portfolio. It is reasonable to keep the effects of the business cycle and uncertainty in the framework in order to understand the variations in the different financial shares. As a consequence, we opt for the benchmark model. 
Table 6: Shares equations full results

(Baseline model specification with no exogenous factors)

\begin{tabular}{|c|c|c|c|c|c|c|}
\hline & M1 & M2M1 & M3M2 & PEL & Assets & Lifebonds \\
\hline Wealth elasticity & $\begin{array}{c}-0.0 \\
(-3.1)\end{array}$ & $\begin{array}{c}0.0 \\
(2.4)\end{array}$ & $\begin{array}{c}-0.1 \\
(-4.4)\end{array}$ & $\begin{array}{c}0.0 \\
- \\
\end{array}$ & $\begin{array}{c}-0.0 \\
(-1.0)\end{array}$ & $\begin{array}{c}0.2 \\
(9.9)\end{array}$ \\
\hline Uncompensated interest rates & & & & & & \\
\hline M1 real rate & $\begin{array}{c}3.4 \\
(5.6) \\
\end{array}$ & $\begin{array}{c}-2.5 \\
- \\
\end{array}$ & $\begin{array}{c}1.1 \\
- \\
\end{array}$ & $\begin{array}{c}-0.1 \\
- \\
\end{array}$ & $\begin{array}{c}-0.2 \\
- \\
\end{array}$ & $\begin{array}{c}-1.8 \\
- \\
\end{array}$ \\
\hline M2 real rate & $\begin{array}{c}-2.5 \\
(-4.2)\end{array}$ & $\begin{array}{c}7.6 \\
(9.6)\end{array}$ & $\begin{array}{c}-3.8 \\
-\end{array}$ & $\begin{array}{c}0.2 \\
-\end{array}$ & $\begin{array}{c}-1.1 \\
-\end{array}$ & $\begin{array}{c}-0.5 \\
-\end{array}$ \\
\hline M3 real rate & $\begin{array}{c}1.1 \\
(2.9) \\
\end{array}$ & $\begin{array}{c}-3.8 \\
(-7.9) \\
\end{array}$ & $\begin{array}{c}3.5 \\
(7.2)\end{array}$ & $\begin{array}{c}-0.4 \\
-\end{array}$ & $\begin{array}{c}-0.9 \\
-\end{array}$ & $\begin{array}{c}0.4 \\
-\end{array}$ \\
\hline PEL real rate & $\begin{array}{c}-0.1 \\
- \\
\end{array}$ & $\begin{array}{c}0.2 \\
-\end{array}$ & $\begin{array}{c}-0.4 \\
-\end{array}$ & $\begin{array}{c}-0.4 \\
-\end{array}$ & $\begin{array}{c}1.2 \\
-\end{array}$ & $\begin{array}{c}-0.5 \\
-\end{array}$ \\
\hline Assets real rate & $\begin{array}{c}-0.2 \\
(-0.9) \\
\end{array}$ & $\begin{array}{c}-1.1 \\
(-4.1) \\
\end{array}$ & $\begin{array}{c}-0.9 \\
(-2.9)\end{array}$ & $\begin{array}{c}1.2 \\
-\end{array}$ & $\begin{array}{c}3.6 \\
(5.7)\end{array}$ & $\begin{array}{c}-2.6 \\
-\end{array}$ \\
\hline Lifebonds real rate & $\begin{array}{c}-1.8 \\
(-4.5)\end{array}$ & $\begin{array}{c}-0.5 \\
(-1.1)\end{array}$ & $\begin{array}{c}0.4 \\
(1.1)\end{array}$ & $\begin{array}{c}-0.5 \\
-\end{array}$ & $\begin{array}{c}-2.6 \\
(-6.1)\end{array}$ & $\begin{array}{c}4.9 \\
(8.3)\end{array}$ \\
\hline
\end{tabular}

Validation Statistics

\begin{tabular}{|l|c|c|c|c|c|c|}
\hline Adjusted $\mathrm{R}^{2}$ & 0.58 & 0.81 & 0.64 & - & 0.62 & 0.83 \\
\hline $\mathrm{DW}$ & 1.02 & 1.24 & 1.56 & - & 1.32 & 1.37 \\
\hline Normality $\chi^{2}(2,5.99)$ & 4.79 & 0.59 & 0.65 & - & 2.21 & 1.22 \\
$(P$ value 5\%) & 0.09 & 0.75 & 0.72 & - & 0.33 & 0.54 \\
\hline ADF test $(1,-2.88)$ & -4.73 & -5.69 & -6.59 & - & -5.83 & -5.99 \\
\hline Autocorrelation $\chi^{2}(3,7.81)$ & 28.78 & 29.25 & 25.33 & - & 38.67 & 31.64 \\
(P value 5\%) & 0.00 & 0.00 & 0.00 & - & 0.00 & 0.00 \\
\hline Arch $\chi^{2}(3,7.81)$ & 2.15 & 4.70 & 4.94 & - & 3.44 & 2.74 \\
(P value 5\%) & 0.54 & 0.19 & 0.18 & - & 0.33 & 0.43 \\
\hline
\end{tabular}

\subsection{Impact of the share acting as residual: Substitution between PEL and M3M2}

Money market fund shares (M3M2) have represented less than 3\% (versus around 7\% for PEL) of French households' total portfolio in recent years. The dynamics of money market fund shares may therefore no longer affect the general behaviour of the financial portfolio. As a consequence, replacing $M 3 M 2$ by $P E L$ as the share used to satisfy the demand theory restrictions should hardly impact the estimated parameters of the modified benchmark model. In this context, the parameters of the equation of M3M2 are obtained by inferring them from the restrictions conditions applied to the whole set of parameters of the dynamic system (Equation 8). The empirical results regarding the modified benchmark model are shown in Table 7. 
Table 7: Shares equations full results

(Baseline model specification with M3M2 as a residual equation)

\begin{tabular}{|c|c|c|c|c|c|c|}
\hline & M1 & M2M1 & M3M2 & PEL & Assets & Lifebonds \\
\hline Wealth elasticity & $\begin{array}{c}-0.1 \\
(-6.0)\end{array}$ & $\begin{array}{l}-0.0 \\
(-0.9)\end{array}$ & -0.0 & $\begin{array}{c}0.0 \\
(-1.7)-\end{array}$ & $\begin{array}{c}-0.0 \\
(-0.5)\end{array}$ & $\begin{array}{c}0.1 \\
(4.1)\end{array}$ \\
\hline \multicolumn{7}{|l|}{ Uncompensated interest rates } \\
\hline M1 real rate & $\begin{array}{c}6.3 \\
(8.5)\end{array}$ & $\begin{array}{l}-1.5 \\
-\end{array}$ & $\begin{array}{c}-0.3 \\
-\end{array}$ & $\begin{array}{l}-1.0 \\
-\end{array}$ & $\begin{array}{c}-0.9 \\
-\end{array}$ & $\begin{array}{l}-2.5 \\
-\end{array}$ \\
\hline M2 real rate & $\begin{array}{l}-1.5 \\
(-1.9)\end{array}$ & $\begin{array}{c}6.3 \\
(5.1)\end{array}$ & $\begin{array}{c}-4.6 \\
-\end{array}$ & 0.7 & $\begin{array}{c}-2.5 \\
-\end{array}$ & $\begin{array}{c}1.6 \\
-\end{array}$ \\
\hline M3 real rate & $\begin{array}{l}-1.0 \\
(-2.7)\end{array}$ & $\begin{array}{c}0.7 \\
(1.4)\end{array}$ & -1.5 & $\begin{array}{c}-0.4 \\
(-0.8)\end{array}$ & $\begin{array}{c}2.4 \\
-\end{array}$ & $\begin{array}{c}-0.2 \\
-\end{array}$ \\
\hline PEL real rate & $\begin{array}{c}-0.3 \\
-\end{array}$ & $\begin{array}{c}-4.6 \\
-\end{array}$ & $\begin{array}{c}-1.5 \\
-\end{array}$ & $\begin{array}{c}6.7 \\
-\end{array}$ & $\begin{array}{c}2.0 \\
-\end{array}$ & $\begin{array}{c}-2.3 \\
-\end{array}$ \\
\hline Assets real rate & $\begin{array}{c}-0.9 \\
(-3.1) \\
\end{array}$ & $\begin{array}{l}-2.5 \\
(-5.5) \\
\end{array}$ & 2.0 & $\begin{array}{c}2.4 \\
(7.3) \\
\end{array}$ & $\begin{array}{c}3.2 \\
(5.6) \\
\end{array}$ & $\begin{array}{c}-4.3 \\
- \\
\end{array}$ \\
\hline Lifebonds real rate & $\begin{array}{l}-2.5 \\
(-5.1)\end{array}$ & $\begin{array}{c}1.6 \\
(2.0)\end{array}$ & -2.3 & $\begin{array}{c}-0.2 \\
(-0.3)\end{array}$ & $\begin{array}{c}-4.3 \\
(-6.0)\end{array}$ & $\begin{array}{c}7.6 \\
(5.9)\end{array}$ \\
\hline $\begin{array}{l}\text { Detrended unemployment } \\
\text { rate }\end{array}$ & $\begin{array}{c}-1.4 \\
(-3.8) \\
\end{array}$ & $\begin{array}{l}-1.0 \\
(-1.5)\end{array}$ & 0.0 & $\begin{array}{c}0.3 \\
(0.5) \\
\end{array}$ & $\begin{array}{c}0.6 \\
(0.6) \\
\end{array}$ & $\begin{array}{c}-1.8 \\
(-1.4)\end{array}$ \\
\hline Financial market volatility & $\begin{array}{c}0.0 \\
(1.3)\end{array}$ & $\begin{array}{c}-0.0 \\
(-2.0)\end{array}$ & 0.0 & $\begin{array}{c}0.0 \\
(0.1)\end{array}$ & $\begin{array}{c}0.0 \\
(1.7)\end{array}$ & $\begin{array}{c}-0.1 \\
(-2.0)\end{array}$ \\
\hline
\end{tabular}

Validation statistics

\begin{tabular}{|l|c|c|c|c|c|c|}
\hline Adjusted $\mathrm{R}^{2}$ & 0.38 & 0.62 & & $0.80-$ & 0.72 & 0.56 \\
\hline DW & 1.61 & 2.17 & & 1.51 & 2.13 & 2.41 \\
\hline Normality $\chi^{2}(2,5.99)$ & 0.88 & 7.92 & & 1.37 & 6.10 & 5.21 \\
$(P$ value 5\%) & 0.64 & 0.02 & & 0.51 & 0.05 & 0.07 \\
\hline ADF test $(1,-2.88)$ & -7.06 & -9.06 & & -6.53 & -8.87 & -10.22 \\
\hline Autocorrelation $\chi^{2}(3,7.81)$ & 27.84 & 31.45 & & 27.19 & 37.76 & 35.60 \\
$(P$ value 5\%) & 0.00 & 0.00 & & 0.00 & 0.00 & 0.00 \\
\hline Arch $\chi^{2}(3,7.81)$ & 0.15 & 11.13 & & 1.76 & 4.67 & 1.58 \\
P value 5\%) & 0.99 & 0.01 & & 0.62 & 0.20 & 0.66 \\
\hline
\end{tabular}

Switching M3M2 and PEL essentially leads to a change in the estimated parameters of the equations of these two shares (see Table 5B and Table 7). The cross-effects of the real interest rates are also comparable in the two models.

However, switching the two shares introduces some slight changes in the effects of the additional exogenous factors. Indeed, even if the coefficients of these factors are quite weak, the estimated coefficients are more significant in the modified benchmark model. 
Concerning the quality of the regressions, the performance of the modified benchmark model is relatively good. Nevertheless, given that the benchmark model explains the dynamics of the most important shares (Lifebonds and M2, which represent around $65 \%$ of total wealth) better, we once again opt for the benchmark model.

\subsection{Reconsideration of the structure of the lags in the benchmark framework}

Our baseline model is similar to the system of equations estimated by Blake (2004), which is characterised by a specific structure of lags. This structure is introduced in the framework to avoid simultaneity biases. In fact, the following structure of lags $\sum_{j=1}^{N-1} \lambda_{i j}^{*} \Delta \theta_{i t-1}$ was replaced by the contemporaneous weighted average $\left(\sum_{j=1}^{N-1} \lambda_{i j}^{*} \Delta \theta_{i t}\right)$ in the benchmark system of equations.

The model estimated in this section makes it possible to impose the simultaneity assumption regarding the shares (simultaneity-based model) as follows (see the system of Equations 7):

$$
\begin{aligned}
\theta_{i t}=a_{i}^{*}+b_{i}^{*} & \ln \left(W_{t}\left(1+r_{w t}\right)\right)+\sum_{j=1}^{N} c_{i j}^{*} \ln \left(1+r_{j t}\right)+\sum_{j=1}^{M} h_{i j}^{*} z_{j t} \\
& +\sum_{s=0}^{K-1} b_{i s}^{*} \Delta \ln \left(W_{t}\left(1+r_{w_{t-s}}\right)\right) \\
& +\sum_{s=0}^{K-1} \sum_{j=1}^{N} c_{i j s}^{*} \Delta \ln \left(1+r_{j t-s}\right)+\sum_{s=0}^{K-1} \sum_{j=1}^{M} h_{i j s}^{*} \Delta \ln \left(z_{j t-s}\right)+\sum_{j=1}^{N-1} \lambda_{i j}^{*} \Delta \theta_{i t}+\zeta_{i t}
\end{aligned}
$$

The single difference between these regressions and those exploited in the previous exercises is related to the last term (before the error term) of the relationships, in bold letters.

The results (see Table 8) are compared to those displayed in Table 5B. The latter are obtained by imposing similar conditions (both demand theory constraints and identical AR processes for the shares).

One can note that:

- The coefficients of the wealth ratio are stable. The change in the specification does not have any impact on the magnitude and standard error of this variable in the equations of the shares;

- The uncompensated interest rates display two different aspects. The coefficients of the own returns (return "i" in the equation of share "i") are robust as the changes of the model do not affect them. The cross-effects of the real returns are more specification-dependent. For example, the M3 return does not influence the share M1 in the benchmark model, whereas it does when the simultaneity hypothesis is imposed. The real returns of Lifebonds significantly contribute to the variations in the M3M2 share, whereas their effects are null in the benchmark model (Table 5B). The same conclusion can be made when analysing the effect of the asset real rate on the M1 share (significant effect with the simultaneity assumption; no effect in the benchmark model);

- The estimation of the simultaneity-based model provides less relevant results in terms of explanatory power. Indeed, the adjusted $\mathrm{R}^{2}$ in this specification are dramatically weaker. The other validation tests are broadly similar for the two specifications.

In general, the benchmark model displays better performances than the simultaneity-based model. 
Table 8: Shares equations with the simultaneity assumption (Baseline model specification with identical AR processes)

\begin{tabular}{|l|c|c|c|c|c|c|}
\cline { 2 - 7 } \multicolumn{1}{c|}{} & M1 & M2M1 & M3M2 & PEL & Assets & Lifebonds \\
\hline Wealth elasticity & -0.1 & 0.0 & -0.0 & 0.0 & -0.0 & 0.2 \\
$(-5.5)$ & $(1.0)$ & $(-1.0)$ & - & $(-1.0)$ & $(6.4)$ \\
\hline Uncompensated interest & & & & & & \\
rates & 5.7 & -2.2 & 1.5 & -0.1 & -1.4 & -3.5 \\
M1 real rate & $(6.7)$ & - & - & - & - & - \\
\hline \multirow{2}{*}{ M2 real rate } & -2.2 & 5.4 & -2.1 & 0.3 & -1.8 & 0.3 \\
\hline \multirow{2}{*}{ M3 real rate } & $(-3.8)$ & $(8.1)$ & - & - & - & - \\
\hline \multirow{2}{*}{ Pel real rate } & 1.5 & -2.1 & 0.8 & -2.3 & 0.2 & 1.9 \\
\hline \multirow{2}{*}{ Assets real rate } & $(2.6)$ & $(-4.0)$ & $(0.7)$ & - & - & - \\
\hline Lifebonds real rate & -0.1 & 0.3 & -2.3 & -0.5 & 2.6 & 0.0 \\
\hline Detrended unemployment & - & - & - & - & - & - \\
\hline rate & -0.9 & 0.2 & -0.4 & 0.0 & 0.5 & 0.4 \\
\hline Financial market volatility & $(-2.1)$ & $(0.5)$ & $(-0.4)$ & - & $(0.5)$ & $(0.4)$ \\
\hline & -0.0 & -0.0 & 0.0 & 0.0 & 0.0 & 0.0 \\
& $(-0.0)$ & $(-0.8)$ & $(1.2)$ & - & $(0.3)$ & $(0.1)$ \\
\hline
\end{tabular}

Validation statistics

\begin{tabular}{|l|c|c|c|c|c|c|}
\hline Adjusted $^{2}$ & -0.38 & 0.66 & 0.17 & - & 0.60 & 0.59 \\
\hline DW & 2.27 & 1.90 & 2.20 & - & 1.77 & 2.03 \\
\hline Normality $\chi^{2}(2,5.99)$ & 0.98 & 10.97 & 3.48 & - & 3.75 & 1.60 \\
(P value 5\%) & 0.61 & 0.00 & 0.18 & - & 0.15 & 0.45 \\
\hline ADF test (1,-2.88) & -9.86 & -8.05 & -9.37 & - & -7.54 & -8.57 \\
\hline Autocorrelation & 28.18 & 24.54 & 26.09 & - & 27.18 & 18.82 \\
(P value 5\%) & 0.00 & 0.00 & 0.00 & - & 0.00 & 0.00 \\
\hline Arch $\chi^{2}(3,7.81)$ & 2.12 & 5.77 & 1.60 & - & 2.22 & 2.25 \\
P value 5\%) & 0.55 & 0.12 & 0.66 & - & 0.53 & 0.52 \\
\hline
\end{tabular}




\section{What would be the consequences in terms of portfolio allocation under the low interest rates assumptions?}

We assume that, over the period 2017-2050, real returns remain at their observed levels at the beginning of 2019. We then compare the results with a baseline scenario in which real yields are kept over the same period at their 1999-2016 averages.

The results are displayed in Table 9. The table shows that sight deposits and equities substitute for passbooks, other monetary assets, bonds and life insurance contracts, and home savings plans are unaffected in spite of a lower yield. For example, Lifebonds decreases in the low interest rate (LIR) scenario ( $49.4 \%$ in the baseline scenario versus $46.5 \%$ in the LIR case) while Assets increases in the same context (13.9\% in the baseline scenario versus $15.5 \%$ in the LIR case). These results reflect the fact that Assets and PEL are complementary, whereas Assets are substitutes for M2M1, M3M2 and Lifebonds. However, there are caveats to be made. One caveat is that we do not use a general equilibrium model; one might question getting a $7.6 \%$ return by investing in shares (1999-2016 average), while real rates remain at very low levels for a protracted period, probably reflecting a "secular stagnation". Another caveat is that not all wealth components are included in our FAIDs and one might expect increased household debt and reallocation towards real estate in a low rate environment.

Table 9: Low rate scenario and comparison with baseline

(In percentage points)

\begin{tabular}{|c|c|c|c|c|}
\hline \multirow[b]{2}{*}{$\begin{array}{l}\text { Real } \\
\text { returns }\end{array}$} & $1999-2016$ & \multicolumn{2}{|c|}{$2017-2050$} & \multirow[b]{2}{*}{$(2)-(1)$} \\
\hline & Observed & Baseline (1) & $\begin{array}{l}\text { Low interest } \\
\text { rates }(2)\end{array}$ & \\
\hline M1 & -1.3 & -1.3 & -1.3 & 0.0 \\
\hline M2M1 & 1.0 & 1.0 & -0.8 & -1.8 \\
\hline M3M2 & 0.7 & 0.7 & -2.0 & -2.6 \\
\hline PEL & 1.4 & 1.4 & -0.8 & -2.2 \\
\hline Assests & 7.6 & 7.6 & 7.6 & 0.0 \\
\hline Lifebonds & $2, .0$ & 2.0 & 0.0 & -2.0 \\
\hline
\end{tabular}

\begin{tabular}{|l|l|l|l|l|}
\cline { 2 - 5 } \multicolumn{1}{c|}{} & $1999-2016$ & \multicolumn{2}{c|}{$2017-2050$} & \multicolumn{1}{c|}{} \\
\cline { 2 - 5 } \multicolumn{1}{c|}{ Shares } & Observed & Baseline (1) & $\begin{array}{c}\text { Low interest } \\
\text { rates (2) }\end{array}$ & (2)-(1) \\
\hline M1 & 11.9 & 10.1 & 13.0 & 2.9 \\
\hline M2M1 & 16.6 & 16.9 & 16.2 & -0.8 \\
\hline M3M2 & 4.1 & 2.3 & 1.4 & -0.9 \\
\hline PEL & 6.8 & 7.4 & 7.4 & 0.0 \\
\hline Assets & 15.9 & 13.9 & 15.5 & 1.6 \\
\hline Lifebonds & 44.7 & 49.4 & 46.5 & -2.9 \\
\hline
\end{tabular}

\section{How does portfolio allocation react to the introduction of a flat tax on savings income?}

From 2018, in order to simplify the taxation of savings income and make it more transparent and less distortive, a flat tax (FT) replaced the various tax regimes of most financial products in France, keeping the overall taxation of savings income unchanged. An assessment of the impact of this reform is carried out, using the previous baseline model and data on the ownership of 
different assets by taxable income brackets, based on the results of the Wealth Survey (INSEE, 2017). Furthermore, the effects of a scenario, which we label "Extended FT" and in which the FT would be extended to all financial products (Pfister, 2018), are also shown.

Table 10 displays the long-term impact on outstanding amounts at end-2017, in variations from the baseline scenario, in percentage points of households' financial wealth and in corresponding amounts. In the long run, the FT would lead to a substitution out of Lifebonds and, to an even lesser extent, M2M1 and M3M2 into Assets and, to a lesser extent, M1, with PEL being unaffected. Indeed, the FT would increase average taxation and thus lower the after tax return on Lifebonds and PEL (more precisely on life insurance contracts) and lower it on Assets (more precisely shares). Furthermore, in the baseline model, Assets are substitutable for Lifebonds (see Lifebonds equation) and complementary to PEL (see PEL equation), the latter effect offsetting the negative impact of the FT on the PEL yield.

An "Extended FT" would also cover so-called A passbooks included in M2M1. The column "Extended FT" in Table 11 shows that the substitutions resulting from the FT as it stands (into Assets and M1 and out of other liquid assets) would be strengthened if the FT were extended to all financial products' income.

Table 10: Impact of a flat tax on savings income

(Deviation from baseline, in percentage points and EUR billions)

\begin{tabular}{|l|c|c|c|c|}
\cline { 2 - 5 } \multicolumn{1}{c|}{} & \multicolumn{2}{c|}{ FT } & \multicolumn{2}{c|}{ Extended FT } \\
\cline { 2 - 5 } \multicolumn{1}{c|}{} & Share & $\begin{array}{c}€ \\
\text { Amount }\end{array}$ & Share & $\begin{array}{c}€ \\
\text { Amount }\end{array}$ \\
\hline M1 & 0,2 & 7,3 & 0,3 & 10,9 \\
\hline M2M1 & $-0,1$ & $-4,4$ & $-0,4$ & $-16,0$ \\
\hline M3M2 & $-0,2$ & $-7,9$ & $-0,1$ & $-1,8$ \\
\hline PEL & 0,0 & $-1,4$ & $-0,1$ & $-1,9$ \\
\hline Assets & 0,8 & 31,5 & 0,9 & 34,0 \\
\hline Lifebonds & $-0,7$ & $-25,2$ & $-0,7$ & $-25,2$ \\
\hline
\end{tabular}

\section{Conclusion}

The benchmark model augmented with some additional exogenous factors validates the FAIDS model as an appropriate framework for satisfactorily describing the dynamics of French households' portfolio. Indeed, this model highlights and quantifies the effects of the core explanatory variables (returns on assets, wealth) but also the roles of some additional exogenous factors. In particular, the model distinguishes the substitution and complementarity effects between financial assets, highlighting the role of wealth as one of the main drivers of the dynamics of certain financial assets and underlining the relative importance of income risk in the dynamics of these assets.

It should be highlighted that even though the preliminary tests detected a break in the dynamics of the shares during the global financial crisis, the quality of the regressions over the period including the early 2010 s remains acceptable. This shows that the financial crisis did not lead to a major shift in French households' portfolio allocation.

Moreover, a range of robustness tests and the validity checks confirm the relevance of the specification implemented in this paper. Specifically:

- The simultaneity-based model provides less relevant results than the baseline model in terms of explanatory power;

- A similar conclusion is reached when replacing M3M2 by PEL, as the share used to satisfy the demand theory restrictions in the dynamic system; 
- Finally, the gain obtained through the introduction of the two exogenous factors (the business cycle indicator and the financial market risk factor) in the framework is marginal. These factors are kept in the system to take into account two empirically founded dimensions in the dynamics of the determination of the financial portfolio.

The simulations carried out by imposing the "Low Interest Rates" assumption from 2017 to 2050 lead to a substitution of passbooks for sight deposits and equities; other monetary assets, bonds and life insurance contracts, and home savings plans are unaffected.

Finally, the assessment of the effects of the flat tax, which has replaced the various tax regimes of most financial products in France, based on the benchmark model, shows a substitution out of life insurance contracts and, to a lesser extent, passbooks and other monetary assets mostly into equities, with home savings plans being unaffected.

As an avenue for future research, this study could be extended, for example, by introducing housing and debt into French households' wealth. 


\section{BIBLIOGRAPHY}

Alston J.M., Chalfant A. (1993). The Silence of the Lambdas: a Test for the Almost Ideal and Rotterdam Models, American Journal of Agricultural Economics, 75, 304-314.

Alston J.M., Foster K.A., Green R. (1994). Estimating Elasticities with the Linear Approximate Ideal Demand System: Some Monte Carlo Results, Review of Economics and Statistics, 76, 351-356.

Amemiya T. (1980). Selection of Regressors, International Economic Review, 21 (2), 331-354.

Amemiya T., (1985). Advanced Econometrics, Cambridge: Harvard University Press.

Bachellerie A., Charavel C., Pfister C. (2016), La destination finale des placements financiers des ménages avant et pendant la crise, 2016, Bulletin de la Banque de France, Mai-Juin, 55-61.

Bai J., Perron P. (1998). Estimating and Testing Linear Models with Multiple Structural Changes, Econometrica, 66, 47-78.

Bai J., Perron P. (2003). Computation and Analysis of Multiple Structural Change Models, Journal of Applied Econometrics, 18 (1), 1-22.

Banque de France. (2015). L'épargne des ménages français: davantage drainée par les produits réglementés qu'orientée par les mécanismes de marché, Focus, No. 14, July 21, https://www.banquefrance.fr/uploads/tx_bdfgrandesdates/Focus_14_FR_02.pdf.

Barten A.P. (1964). Consumer Demand Functions under Conditions of Almost Additive Preferences, Econometrica, 32, 1-38.

Barten A.P. (1977). The Systems of Consumer Demand Functions Approach: A Review, Econometrica, 45, 23-51.

Banks J, Blundell R, Lewbel A. (1997). Quadratic Engel Curves and Consumer Demand, Review of Economics and Statistics, 79, 527-539.

Barnett W.A., Choi S. (1989). A Monte Carlo Study of Tests of Blockwise Weak Separability, Journal of Business and Economic Statistics, 7, 363-377.

Barnett W.A., Lee W.Y., Wolfe M.D. (1987). The Global Properties of the Two Minflex Laurent Flexible Functional Forms, Journal of Econometrics, 36, 281-298.

Barnett W.A., Seck O. (2008). Rotterdam Model versus Almost Ideal Demand System: Will The Best Specification Please Stand up, Journal of Applied Econometrics, 23, 795-824.

Barr D. G., Cuthbertson K. (1991). Neoclassical Consumer Demand Theory and the Demand for Money, Economic Journal, 101(407), 855-876.

Barr D.G., Cuthbertson K. (1994). The Demand for Financial Assets Held in the UK by the Overseas Sector, The Manchester School, 62(1), 1-20.

Blake D. (2004). Modelling the Composition of Personal Sector Wealth in the UK, Applied Financial Economics, 14, 611-630.

Christensen L.R., Jorgenson D.W., Lau LJ. (1975). Transcendental Logarithmic Utility Functions, American Economic Review, 65, 367-383.

Christofides L.N. (1976). Quadratic Costs and Multi-asset Partial Adjustment Equations, Applied Econometrics, 8, 301-305. 
Chua C. L., Griffiths W.E., O’ Donnell C.J. (2001). Bayesian Model Averaging in Consumer Demand Systems with Inequality Constraints, Canadian Journal of Agricultural Economics, Vol.49, issue 3, 269291.

Cooper R.J., McLaren K.R. (1996). A System of Demand Equations Satisfying Effectively Global Regularity Conditions, Review of Economics and Statistics, 78(2), 359-364.

Deaton A, Muellbauer J. (1980a). An Almost Ideal Demand System. American Economic Review, 70, $312-326$

Deaton A., Muellbauer J. (1980b). Economics and Consumer Behavior, Cambridge University Press: Cambridge, UK.

Diewert W.E. (1971). An Application of the Shephard Duality Theorem: a Generalized Leontief Production Function, Journal of Political Economy, 79, 461-507.

Erkan E. (2006). Demand Systems for Agricultural Products in OECD Countries, Applied Economics Letters, 13, 163-169.

Fousekis P, Revell B. J. (2000). Meat Demand in UK: A Differential Approach, Journal of Agricultural and Applied Economics, 32, 11-19.

Fousekis P, Revell B. J. (2005). Retail Fish Demand in Great Britain and its Fisheries management Implications, Marine Resource Economics, 19, 495-510.

Grimes A., Wong A. Y.-T., Meads C.S. (1994). A Note on the Correct Specification of Financial Portfolio AIDS Models, European Economic Review, 38, 1171-1174.

Hunt B.F., Upsher M.R. (1979). Generalized Adjustment of Assets Equations, Australian Economic Papers, 18(33), 308-321.

INSEE. (2012). Méthodologie des comptes trimestriels, Insee Méthodes, 126,35-37.

INSEE. (2017). Patrimoine et endettement des ménages en 2015 et séries longues - Enquête Patrimoine, Insee Résultats, 28 novembre, https://www.insee.fr/fr/statistiques/2908186.

Kabe S., Kanazawa Y. (2014). Estimating the Markov-Switching Almost Ideal Demand Systems: A Bayesian Approach, Empirical Economics, 47, 1193-1220.

Kastens T. L., Brester G.W. (1996). Model Selection and Forecasting Ability of Theory Constrained Food Demand Systems, American Journal of Agriculture Economics, 78(2), 301-312.

Katchova A.L., Chern W. (2004). Comparison of Quadratic Expenditure System and Almost Ideal Demand System Based on Empirical Data, International Journal of Applied Economics, 1(1), 55-64.

Lee J.Y., Brown M.G., Seale J.L. (1994). Model Choice in Consumer Analysis: Taiwan, 1970-89, American Journal of Agricultural Economics, 76(3), 504-512.

Lewbel A. (1989). Nesting the AIDS and Translog Demand Systems. International Economic Systems, International Economic Review, 30(2), 349-356.

Meyer S., Yu X. Abler D. (2011). Comparison of Several Demand Systems. Paper for the Agricutural \& Applied Economics Association, Pennsylvania, July.

Monfront R., Paul, L., Pfister C. (2005). La fiscalité des revenus de l'épargne, in Croissance équitable et concurrence fiscale, Christian Saint-Etienne and Jacques Le Cacheux (eds), Conseil d'Analyse économique, 247-266.

Moosa I.A., Baxter J.L. (2002). Modeling the Trend and Seasonal within an AIDS Model of Demand for Alcoholic Beverage in the United Kingdom, Journal of Applied Econometrics, 17(2), 95-106. 
Moschini G. (1995). Units of Measurement and the Stone index in Demand System Estimation, American Journal of Agricultural Economics, 77: 63-68.

Ozuna T., Gomez I.A. (1994). Estimating a System of Recreation Demand Functions Using a Seemingly Unrelated Poisson Regression Approach, Review of Economics and Statistics, 76(2), 356-60.

Pashardes A. (1993). Bias in the Estimation of the Almost Ideal Demand System with the Stone Index Approximation, The Economic Journal, 103, 908-915.

Pfister C. (2018). Fiscalité de l'Épargne et Choix de Portefeuille des Ménages Français, Revue d'économie financière, 131, 61-75.

Pollack R.A., Wales T.J. (1978). Estimation of Complete Demand System from Household Budget Data: the Linear and Quadratic Expenditure System, American Economic Review, 68(3), 348-359.

Pollack R.A., Wales T.J. (1980). Comparison of the Quadratic Expenditure System and Translog Demand Systems with Alternative Specifications of Demographic Effects, Econometrica, 48(3), 595-612.

Theil H. (1965). The Information Approach to Demand Analysis, Econometrica, 33, 67-87.

Theil H. (1975a). Theory and Measurement of Consumer Demand, Vol. 1. North-Holland: Amsterdam.

Theil H. (1975b). Theory and Measurement of Consumer Demand, Vol. 2. North-Holland: Amsterdam.

Törnqvist L. (1936). The Bank of Finland's Consumption Price Index. Bank of Finland Monthly Bulletin, 10, 1-8. 